\title{
Spongy Materials Based on Supramolecular Polymer Networks for Detection and Separation of Broad Spectrum Pollutants
}

\author{
Qi Lin, ${ }^{*}{ }^{\dagger}$ Xiao-Wen Guan, ${ }^{\dagger}$ You-Ming Zhang, ${ }^{*}, \dagger,+$ Jiao Wang,${ }^{\dagger}$ Yan-Qing Fan, ${ }^{\dagger}$ Hong Yao, ${ }^{\dagger}$
}

\author{
Tai-Bao Wei*, ${ }^{*}$
}

${ }^{\dagger}$ Qi Lin, Xiao-Wen Guan, Jiao Wang, Yan-Qing Fan, Hong Yao, Tai-Bao Wei. Key Laboratory of Eco-Environment-Related Polymer Materials, Ministry of Education of China; Research Center of Gansu Military and Civilian Integration Advanced Structural Materials; College of Chemistry and Chemical Engineering, Northwest Normal University, Lanzhou, 730070, China; E-mail: linqi2004@126.com; weitaibao@126.com.

$\$$ You-Ming Zhang. College of Chemistry and Chemical Engineering, Lanzhou City University, Lanzhou, Gansu, 730070, China; E-mail: zhangnwnu@126.com.

\section{Suporting Informaltion:}

Number of pages: 37 (S1-S37)

Number of Figure: 45 (Figure S1-S45)

Number of Table: 6 (Table S1-S6) 


\section{Table of Contents}

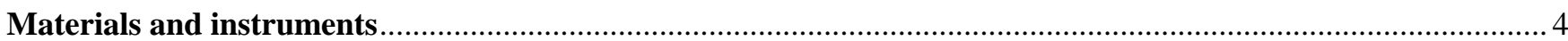

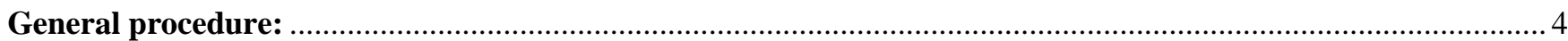

Figure S1. ${ }^{1} \mathrm{H}$ NMR spectrum of compound $\mathbf{L}\left(\mathrm{CDCl}_{3}, 600 \mathrm{MHz}, 298 \mathrm{~K}\right)$......................................................... 7

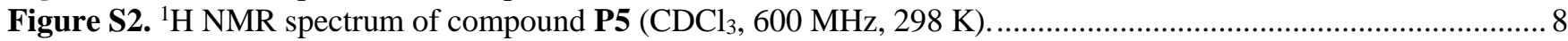

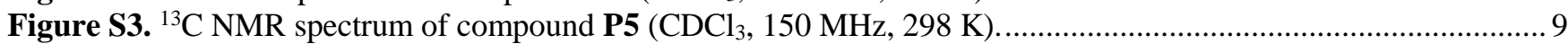

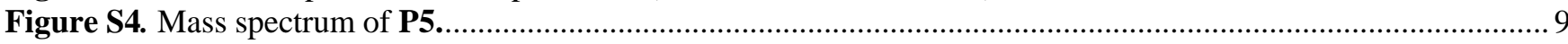

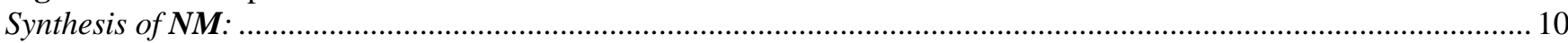

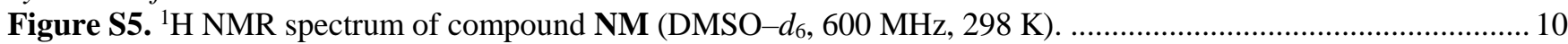

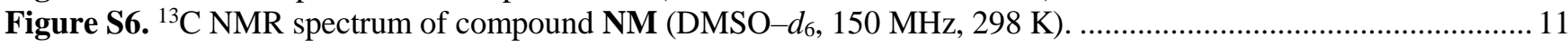

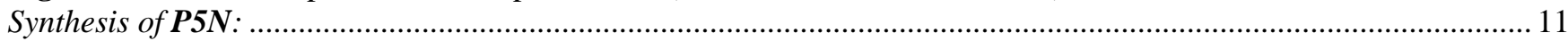

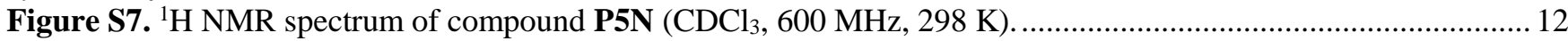

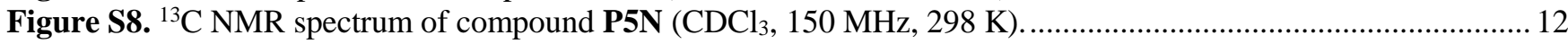

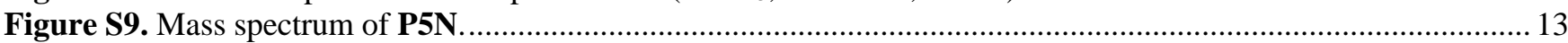

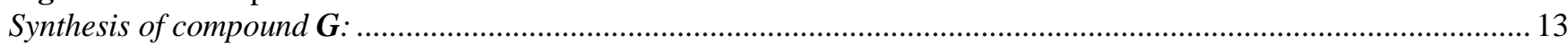

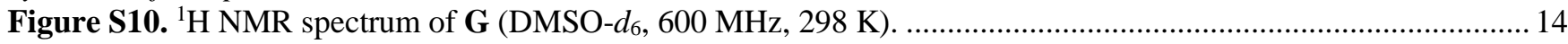

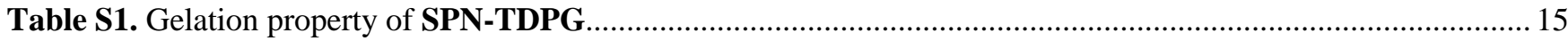

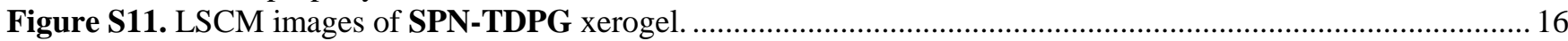

Figure S12. Nitrogen adsorption-desorption isotherm (77.0 K) of SPN-TDPG ................................................... 16

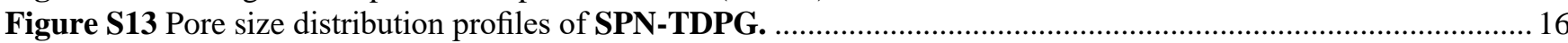

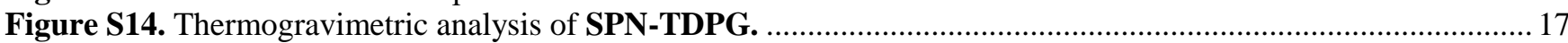

Table S2. Water regain analysis of SPN-TDPG. The water regain (expressed as weight percent) of the SPN-TDPG was determined from the average $(87.4 \%)$ of three measurements...................................................................... 17

Figure S15. Partial 2D NOESY NMR spectrum of $5.0 \mathrm{mM}$ P5N and G in DMSO- $d_{6}$ solution $(600 \mathrm{MHz}, 298 \mathrm{~K}) \ldots . .18$

Figure S16. Partial ${ }^{1} \mathrm{H}$ NMR spectra $\left(600 \mathrm{MHz}, 298 \mathrm{~K}\right.$ ) of P5N in DMSO- $d_{6}$ at various concentrations: (a) $1.0 \mathrm{mM}$; (b)

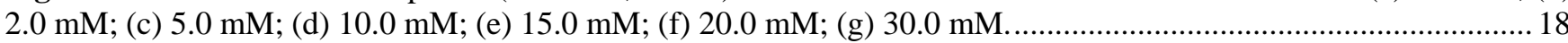

Figure S17. FT-IR spectra of powdered P5N, xerogel SPN-TDPG....................................................................... 19

Figure S18. Partial ${ }^{1} \mathrm{H}$ NMR spectra (600 MHz, DMSO- $d_{6}, 298 \mathrm{~K}$ ) of P5N and $\mathbf{G}$ at different concentrations: (a) 5.0

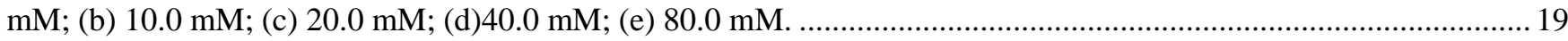

Figure S19. Representative SEM images showing the morphology of (a) P5N and (b) SPN-TDPG.......................22

Figure S20. HR-ESI-MS of mixture P5N and G, clearly indicating the $2: 1$ stoichiometry for P5N and G. ...............20

Figure S21. The linear range of (a) SPN-TDPG for $\mathrm{Fe}^{3+}$; (b) SPN-TDPG for $\mathrm{Hg}^{2+}$; (c) SPN-TDPG-Fe for F-; (d)

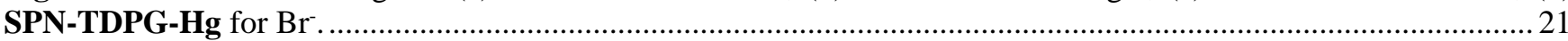

Table S3. Limits of detection the SPN-TDPG or SPN-TDPG treated by metal ions for target ions..........................21

Figure S22. The control experiments: (a) SPN-TDPG treated by water solutions of various cations; (b) SPN-TDPG contained water solutions of various cations treated by water solution of $\mathrm{Fe}^{3+}$; (c) SPN-TDPG treated by water solutions of various cations; (d) SPN-TDPG contained water solutions of various cations treated by water solution of

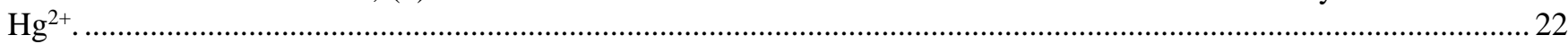

Figure S23. Fluorescence spectra of supramolecular gel (in gelated state) (a) SPN-TDPG-Fe and SPN-TDPG-Fe + F-; (b) SPN-TDPG-Hg and SPN-TDPG-Hg + Br; (c) The fluorescent titrations of SPN-TDPG-Fe for F-; (d) The

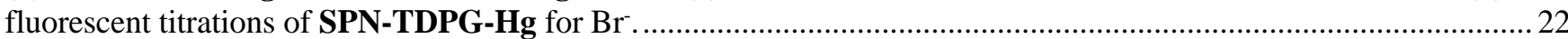

Figure S24. The control experiments: (a) SPN-TDPG-Fe and SPN-TDPG-Fe treated by water solutions of various anions; (b) SPN-TDPG-Fe and SPN-TDPG-Fe contained water solutions of various anions treated by water solution of F- $^{-}$(c) SPN-TDPG-Hg and SPN-TDPG-Hg treated by water solutions of various anions; (d) SPN-TDPG-Hg and SPN-TDPG-Hg contained water solutions of various anions treated by water solution of $\mathrm{Br}^{-}$....................................2 23

Table S4. Chemical name, chemical structures and exact weight of pollutants. .....................................................2 24

Figure S25. A plot of concentration vs. absorbance intensity is shown. (a) methylene blue; (b) Bismarck brown Y; (c) Giemsa's stain; (d) orangel I; (e) methyl orangel; (f) rhodamine B; (g) Sudan I; (h) Sudan II; (i) picric acid; (j) 1-naphthol; (k) $\mathrm{KMnO}_{4}$; (1) $\mathrm{K}_{2} \mathrm{Cr}_{2} \mathrm{O}_{7}$.

Table S5. The required contact time to reach equilibrium on the pollutants adsorptions. The amount of the adsorbent used in this study is $0.5 \mathrm{mg} / \mathrm{mL}$

Figure S26. Pseudo-second-order plots for SPN-TDPG: (a) methylene blue; (b) Bismarck brown Y; (c) Giemsa's stain; (d) orangel I; (e) methyl orangel; (f) rhodamine B; (g) Sudan I; (h)Sudan II; (i) picric acid; (j) 1-naphthol; (k) $\mathrm{KMnO}_{4}$; (l) $\mathrm{K}_{2} \mathrm{Cr}_{2} \mathrm{O}_{7}$. Here $t(\mathrm{~min})$ is the contact time of each pollutant solution with SPN-TDPG and $q_{\mathrm{t}}(\mathrm{mg} / \mathrm{mg})$ is the amount of each pollutant adsorbed per gram of SPN-TDPG

Table S6. Rates of each pollutant uptake by SPN-TDPG. 
Figure S27. UV-vis spectra recorded before (red line)- after (black line, 40min) of adsorption (a) methyl orange, (b)

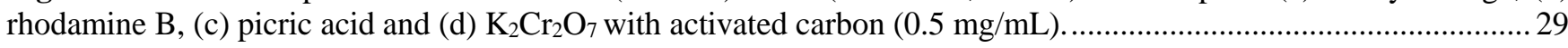

Figure S28. SEM images showing the morphology of regeneration SPN-TDPG.............................................. 29

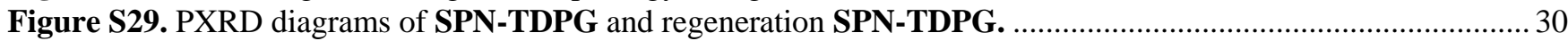

Figure S30. FT-IR spectra of SPN-TDPG and regeneration SPN-TDPG. ............................................... 30

Figure S31. Partial ${ }^{1} \mathrm{H}$ NMR spectra of SPN-TDPG in DMSO- $d_{6}$ with different equivalent $\mathrm{Hg}^{2+}$ (a) 0 equiv.; (b) 0.2

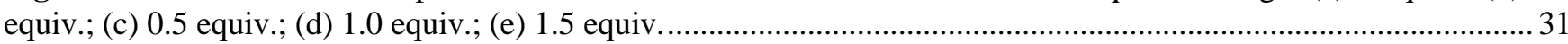

Figure S32. FT-IR spectra of xerogel of SPN-TDPG, SPN-TDPG-Hg and SPN-TDPG-Hg + Br-..................... 31

Figure S33. SEM images showing the morphology of (a) SPN-TDPG-Hg; (b) SPN-TDPG-Hg+Br-.................... 32

Figure S34. Partial ${ }^{1} \mathrm{H}$ NMR spectra of SPN-TDPG in DMSO- $d_{6}$ with different equivalent pyridine (a) 0 equiv.; (b)

0.2 equiv.; (c) 0.5 equiv.; (d) 1.0 equiv........................................................................................ 32

Figure S35. Partial ${ }^{1} \mathrm{H}$ NMR spectra of SPN-TDPG in DMSO- $d_{6}$ with different equivalent $\mathrm{K}_{2} \mathrm{Cr}_{2} \mathrm{O}_{7}$ (a) 0 equiv.; (b)

0.2 equiv.; (c) 0.5 equiv.; (d) 1.0 equiv.; (e) 1.5 equiv........................................................................... 32

Figure S36. Partial ${ }^{1} \mathrm{H}$ NMR spectra of SPN-TDPG in DMSO- $d_{6}$ with different equivalent $\mathrm{KMnO}_{4}$ (a) 0 equiv.; (b)

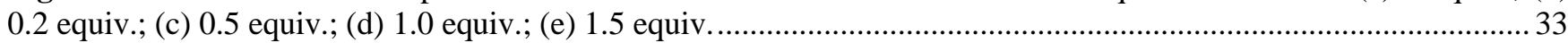

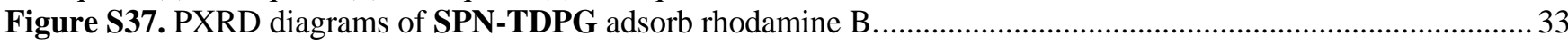

Figure S38. FT-IR spectra of SPN-TDPG adsorb rhodamine B ............................................................. 34

Figure S39. Representative SEM images showing the morphology of SPN-TDPG adsorbed (1) methylene blue; (2) bismarck brown Y; (3) giemsa's stain; (4) orangel I; (5) methyl orangel; (6)rhodamine B; (7) sudan I; (8) sudan II; (9)

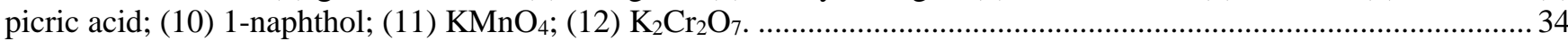
Figure S40. Partial ${ }^{1} \mathrm{H}$ NMR titration spectra $(600 \mathrm{MHz}, 298 \mathrm{~K})$ of $3.0 \mathrm{mM}$ SPN-TDPG with various equivalents of methyl orangel in DMSO- $d_{6}$ solution. (a) SPN-TDPG; (b) 0.5 equiv.; (c) 1.0 equiv.; (d) 2.0 equiv.; (e) 3.0 equiv.; (f) methyl orangel.

Figure S41. Partial 2D NOESY NMR spectrum of $3.0 \mathrm{mM}$ SPN-TDPG and methyl orangel in DMSO- $d_{6}$ solution

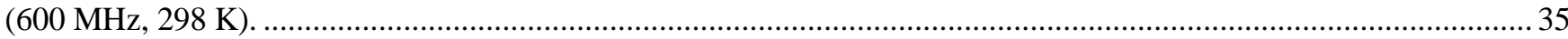

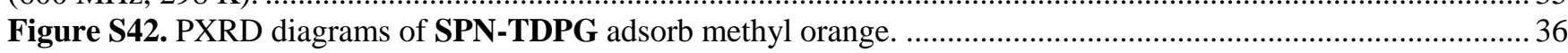

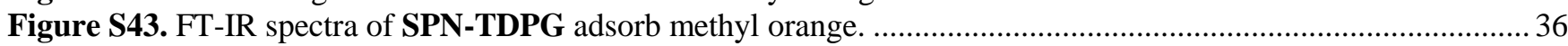

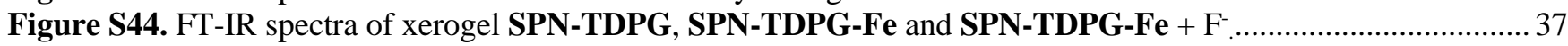

Figure S45. Representative SEM images showing the morphology of (a) SPN-TDPG-Fe; (b) SPN-TDPG-Hg; (c) SPN-TDPG-Fe+F-' (d) SPN-TDPG-Hg+Br- 


\section{Materials and instruments}

All cations were used as the perchlorate salts, while all anions were used as the sodium salts, which were purchased from Alfa Aesar and used as received. All dyes were used as the analytical purity, which purchased from Aladdin. Fresh double distilled water was used throughout the experiment. Nuclear magnetic resonance (NMR) spectra were recorded on Varian Mercury 400 and Varian Inova 600 instruments. Mass spectra were recorded on a Bruker Esquire 6000 MS instrument. The X-ray diffraction analysis (XRD) was performed in a transmission mode with a Rigaku RINT2000 diffractometer equipped with graphite monochromated CuKa radiation $(\lambda=1.54073 \AA$ ) . The morphologies and sizes of the xerogels were characterized using field emission scanning electron microscopy (FE-SEM, JSM-6701F) at an accelerating voltage of $8 \mathrm{kV}$. The infrared spectra were performed on a Digilab FTS-3000 Fourier transform-infrared spectrophotometer. Melting points were measured on an X-4 digital melting-point apparatus (uncorrected). Fluorescence spectra were recorded on a Shimadzu RF-5301PC spectrofluorophotometer. Ultraviolet-visible (UV-vis) spectra were recorded on a Shimadzu UV-2550 spectrometer. Thermogravimetric Analysis (TGA) was carried out on a DSCQ1000 Thermal Gravimetric Analyzer. Surface area measurements were conducted on a BELSORP-Max Accelerated Surface Area and Porosimetry Analyzer. The sample was degassed at $100{ }^{\circ} \mathrm{C}$ for $12.0 \mathrm{~h}$ and then backfilled with $\mathrm{N}_{2} . \mathrm{N}_{2}$ isotherms were generated by incremental exposure to ultra high purity nitrogen up to $1.0 \mathrm{~atm}$ in a liquid nitrogen bath $(77.0 \mathrm{~K})$, and surface parameters were determined using BET adsorption models included in the instrument SPNtware (BELSORP-Max).

\section{General procedure:}

\section{Organogel preperation:}

The mixture of host P5N (5.0 mg) and guest G (5.0 mg) were added into cyclohexanol (0.2 mL), the mixture was heated dissolve, then cooled to room temperature, obtaining stable gel (organogel, yellow). 


\section{Xerogel preparation:}

The organogel was heated to dissolve, then it was dumped on the clear glass plate and aired at room temperature, obtaining the xerogel.

\section{3. ${ }^{1} \mathrm{H}$ NMR experiment:}

\section{(1). The host (P5N)-guest (G) ${ }^{1}$ H NMR titration:}

The P5N (5 mg, $\left.3.17 \times 10^{-6} \mathrm{~mol}\right)$ was dissolved in the DMSO- $d_{6}(0.5 \mathrm{~mL})$, then a series of different equivalents of $\mathbf{G}$ (i.e. 0.2 equiv., 0.5 equiv., 1.0 equiv., 1.5 equiv., 2.0 equiv., 2.5 equiv., 3.0 equiv.,) were added into the solution of $\mathbf{P 5 N}$ and recorded their ${ }^{1} \mathrm{H}$ NMR, respectively.

\section{(2). The concentrations-dependent ${ }^{1} \mathrm{H}$ NMR of P5N:}

A serious of DMSO- $d_{6}$ solutions of P5N with different concentrations ((a) $1.0 \mathrm{mM}$; (b) $2.0 \mathrm{mM}$; (c) $5.0 \mathrm{mM}$; (d) $10.0 \mathrm{mM}$; (e) $15.0 \mathrm{mM}$; (f) $20.0 \mathrm{mM}$; (g) $30.0 \mathrm{mM}$ ) were prepared. Then record their ${ }^{1} \mathrm{H}$ NMR, respectively.

\section{(3). The host (SPN-TDPG)-guest $\left(\mathrm{Hg}^{2+}\right){ }^{1} \mathrm{H}$ NMR titration:}

The xerogel of the SPN-TDPG (5 mg) was dissolved in the DMSO- $d_{6}(0.5 \mathrm{~mL})$, then different equivalents ( 0 equiv.; 0.2 equiv.; 0.5 equiv.; 1.0 equiv.; 1.5 equiv) of $\mathrm{Hg}^{2+}(0.1 \mathrm{M}$, in DMSO-d6) were added into the DMSO- $d_{6}$ solutions of the SPN-TDPG and record their ${ }^{1} \mathrm{H}$ NMR, respectively.

\section{(4). The host (SPN-TDPG-Hg)-guest $\left(\mathrm{Br}^{-}\right){ }^{1} \mathrm{H}$ NMR titration:}

The xerogel of the SPN-TDPG-Hg $(5 \mathrm{mg})$ was dissolved in the DMSO- $d_{6}(0.5 \mathrm{~mL})$, then different equivalents ( 0 equiv.; 0.2 equiv.; 0.5 equiv.; 1.0 equiv.; 1.5 equiv) of $\mathrm{Br}^{-}\left(0.1 \mathrm{M}\right.$, in DMSO- $\left.d_{6}\right)$ were added into the DMSO- $d_{6}$ solutions of the SPN-TDPG and record their ${ }^{1} \mathrm{H}$ NMR, respectively.

\section{Fluorescence titration:}

\section{(1). Fluorescence titration based on different concentrations cations:}

A serious of the SPN-TDPG gels with different concentrations (0.05 equiv., 0.1 equiv., 0.15 equiv., 0.2 equiv., and so on) metal ions $\left(\mathrm{Fe}^{3+}\right.$ and $\left.\mathrm{Hg}^{2+}\right)$ were prepared by dissolving P5N (5 mg), G (5 mg) 
and proper equivalent of metal salt in cyclohexanol $(0.25 \mathrm{~mL})$. Then record their fluorescence intensity at $528 \mathrm{~nm}$ wavelength.

\section{(2). Fluorescence titration based on different equivalent anions:}

The metal-SPN-TDPG (SPN-TDPG-Fe or SPN-TDPG-Hg) gels with different equivalents $(0.1$ equiv., 0.2 equiv., 0.3 equiv., 0.4 equiv., 0.5 equiv. and so on) of anions ( $\mathrm{F}^{-}$or $\left.\mathrm{Br}^{-}\right)$were prepared by dissolve SPN-TDPG, metal ions and proper equivalent of anions salt in cyclohexanol (0.2 mL). Then record their fluorescence intensity at the 528nm wavelength and the limit of detection (LOD) calculated on the basis of $3 \sigma / \mathrm{m}$ method.

\section{Pollutant removal experiments:}

We performed the experiments of pollutant removal at room temperature $\left(25.0^{\circ} \mathrm{C}\right)$ in water. Firstly, 0.0025 g SPN-TDPG xerogel was transferred to a $5.0 \mathrm{~mL}$ glass sample bottle. A pollutant stock solution $(10 \mu \mathrm{M}, 5.0 \mathrm{~mL})$ was added to the glass sample bottle. The mixture was stirred and the suspension in the bottle $(1.00 \mathrm{~mL})$ was taken by a syringe at different intervals and then filtered immediately by using a LABMAX $0.2 \mu \mathrm{m}$ membrane filter. UV-vis spectroscopy was used to determine the residual concentration of the pollutants in each sample.

\section{Water regain analysis:}

Water regain is an important property of the materials for water treatment. SPN-TDPG was dispersed in deionized water for 1.00 hour and then the wet SPN-TDPG was filtered by using filter paper. The polymer was collected and blotted by using additional filter paper, and then weighed. These experiments were carried out with three replicates to find the average as the water regain of the SPN-TDPG. The water regain of SPN-TDPG, which is expressed as the weight percent, was determined from the average of three measurements. 


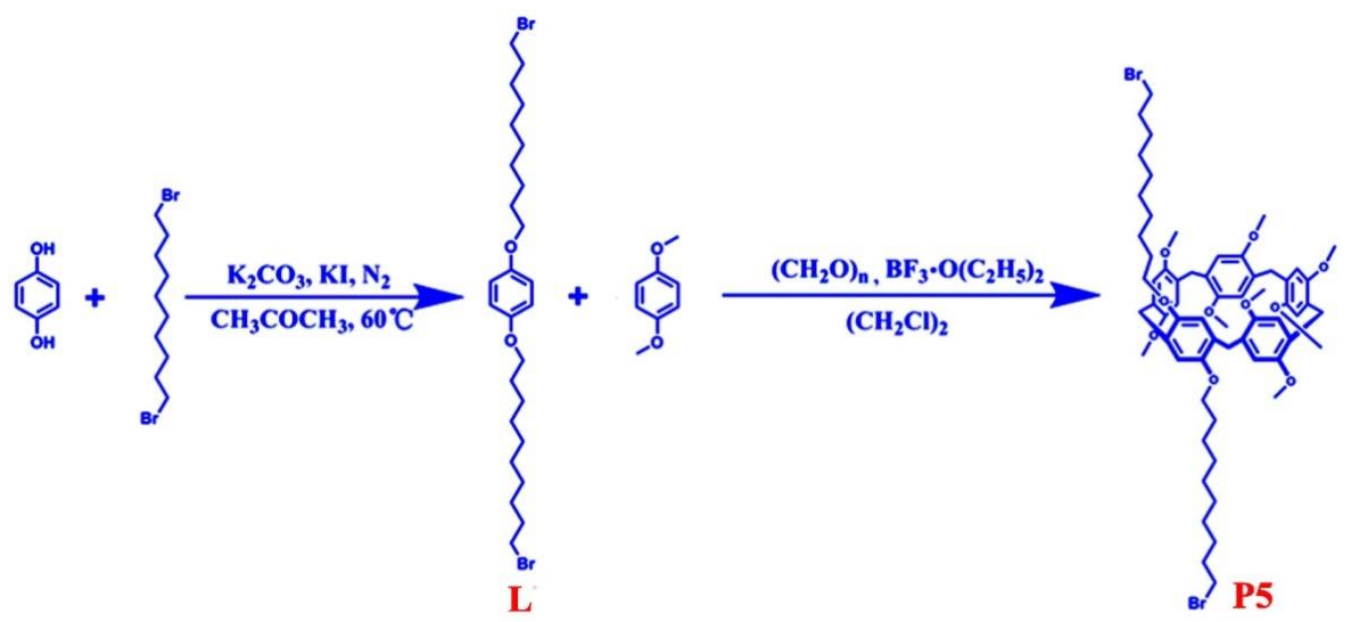

The mixture of 1,10-dibromodecane $(1.20 \mathrm{~g}, 4.0 \mathrm{mmol})$ and $\mathrm{KI}(0.66 \mathrm{~g}, 4.0 \mathrm{mmol})$ was added to a solution of $\mathrm{K}_{2} \mathrm{CO}_{3}(0.14 \mathrm{~g}, 1.0 \mathrm{mmol})$ and hydroquinone $(0.11 \mathrm{~g}, 1.0 \mathrm{mmol})$ in acetone $(200 \mathrm{~mL})$. The mixture was heated under nitrogen atmosphere at reflux for $72 \mathrm{~h}$. The solid was filtered and the solvent was removed. The residue was recrystallized in dichloromethane and petroleum ethers. The product $\mathbf{L}$ was collected by filtration, and dried under vacuum $(0.45 \mathrm{~g}, 82 \%)$. Mp: $83-85{ }^{\circ} \mathrm{C}$. The ${ }^{1} \mathrm{H}$ NMR spectrum of $\mathbf{L}$ is shown in FigureS1. ${ }^{1} \mathrm{H}$ NMR $\left(600 \mathrm{MHz}, \mathrm{CDCl}_{3}\right) . \delta 6.81(\mathrm{~s}, 4 \mathrm{H}), 3.89(\mathrm{t}, J=$ $4.4 \mathrm{~Hz}, 4 \mathrm{H}), 3.40(\mathrm{t}, J=4.4 \mathrm{~Hz}, 4 \mathrm{H}), 1.87-1.82(\mathrm{~m}, 4 \mathrm{H}), 1.77-1.72(\mathrm{~m}, 4 \mathrm{H}), 1.46-1.30$ (m, 24H).

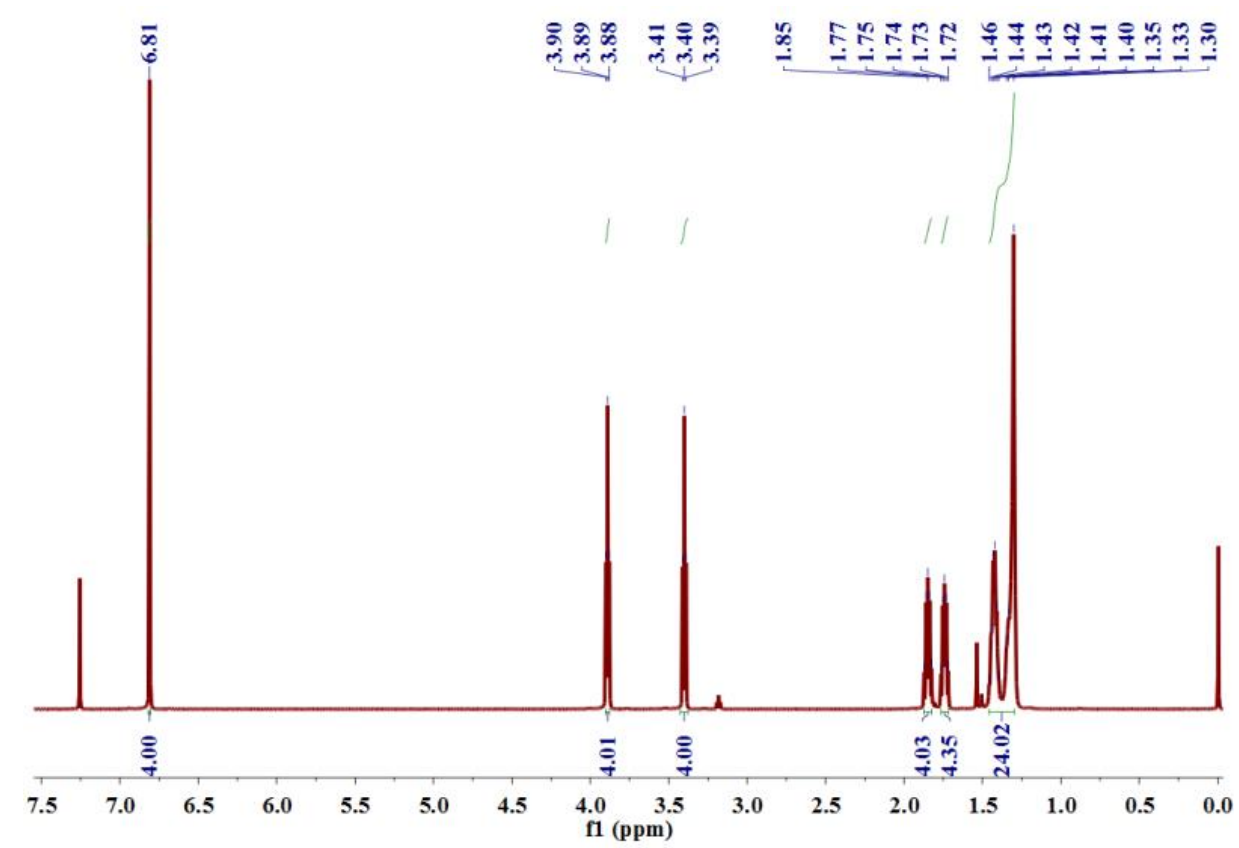

Figure S1. ${ }^{1} \mathrm{H}$ NMR spectrum of compound $\mathbf{L}\left(\mathrm{CDCl}_{3}, 600 \mathrm{MHz}, 298 \mathrm{~K}\right)$.

To a solution of 1,4-dimethoxybenzene $(3.36 \mathrm{~g}, 24.0 \mathrm{mmol})$ and $\mathrm{L}(1.60 \mathrm{~g}, 3.0 \mathrm{mmol})$ in 1,2-dichloroethane $(200 \mathrm{~mL})$ was added paraformaldehyde $(0.75 \mathrm{~g}, 25.0 \mathrm{mmol})$. Then, boron 
trifluoride diethyl etherate $\left(\mathrm{BF}_{3} \mathrm{O}\left(\mathrm{C}_{2} \mathrm{H}_{5}\right)_{2}, 4.5 \mathrm{ml}\right)$ was added to the solution, and the mixture was stirred at $30{ }^{\circ} \mathrm{C}$ for $15-30 \mathrm{~min}$. The solution was poured into water $(100 \mathrm{~mL})$ to quench the reaction. The mixture was filtered and the solvent was removed. The residue was dissolved in dichloromethane. The organic layer was dried over anhydrous $\mathrm{Na}_{2} \mathrm{SO}_{4}$ and evaporated to afford the crude product, which was isolated by column chromatography using ethyl acetate/petroleum ether (v/v, 1:40) to give $\mathbf{P 5}$ as a white solid (1.39 g, $40 \%$ ). Mp: $111-113{ }^{\circ} \mathrm{C}$. The proton NMR spectrum of P5 is shown in FigureS2. ${ }^{1} \mathrm{H}$ NMR $\left(600 \mathrm{MHz}, \mathrm{CDCl}_{3}\right) \delta(\mathrm{ppm}): 6.95-6.86(\mathrm{~m}, 10 \mathrm{H}), 3.94(\mathrm{t}, \mathrm{J}=$ $4.4 \mathrm{~Hz}, 4 \mathrm{H}), 3.79$ (s, 10H), 3.77-3.76 (m, 28H), 1.87-1.82 (m, 6H), 1.54-1.50 (m, 7H), $1.33(\mathrm{~m}, 7 \mathrm{H})$, $1.17(\mathrm{~s}, 6 \mathrm{H}), 0.88-0.86(\mathrm{~m}, 6 \mathrm{H})$. The $13 \mathrm{C}$ NMR spectrum of $\mathbf{P 5}$ is shown in FigureS3. ${ }^{13} \mathrm{C}$ NMR $\left(150 \mathrm{MHz}, \mathrm{CDCl}_{3}\right) \delta(\mathrm{ppm}): 150.27,150.19,150.16,149.51,128.10,128.07,127.95,114.06,113.47$, 113.03, 112.98, 112.93, 67.86, 55.46, 55.25, 55.21, 33.85, 32.16, 29.21, 29.09, 28.07, 27.73. ESI-MS is shown in FigureS4: $\mathrm{m} / \mathrm{z}\left[\mathrm{M}+\mathrm{NH}_{4}\right]^{+}$calcd. for $\mathrm{C}_{63} \mathrm{H}_{88} \mathrm{Br}_{2} \mathrm{NO}_{10}$ 1178.4769, found 1178.4758 .

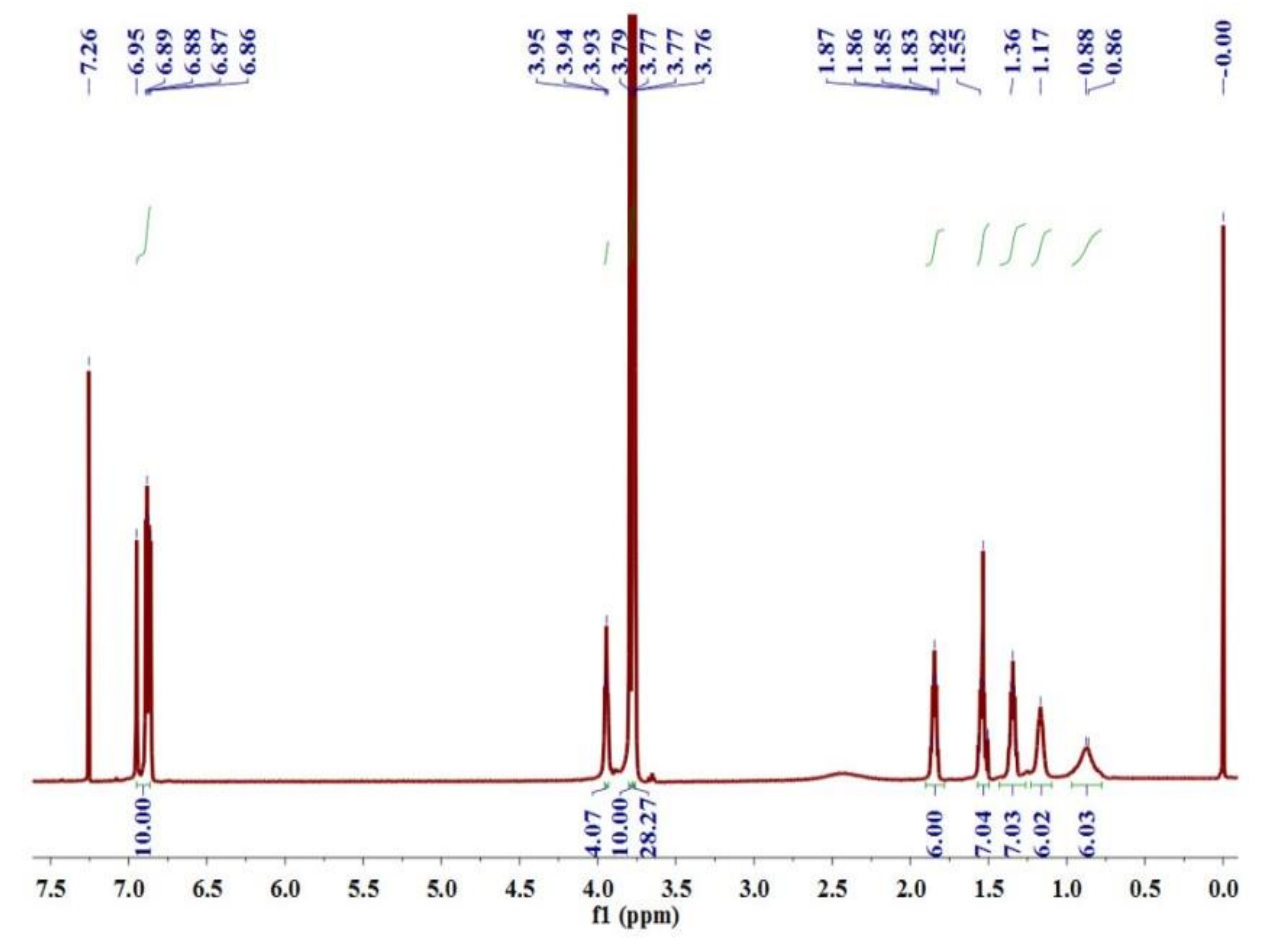

Figure S2. ${ }^{1} \mathrm{H}$ NMR spectrum of compound P5 $\left(\mathrm{CDCl}_{3}, 600 \mathrm{MHz}, 298 \mathrm{~K}\right)$. 


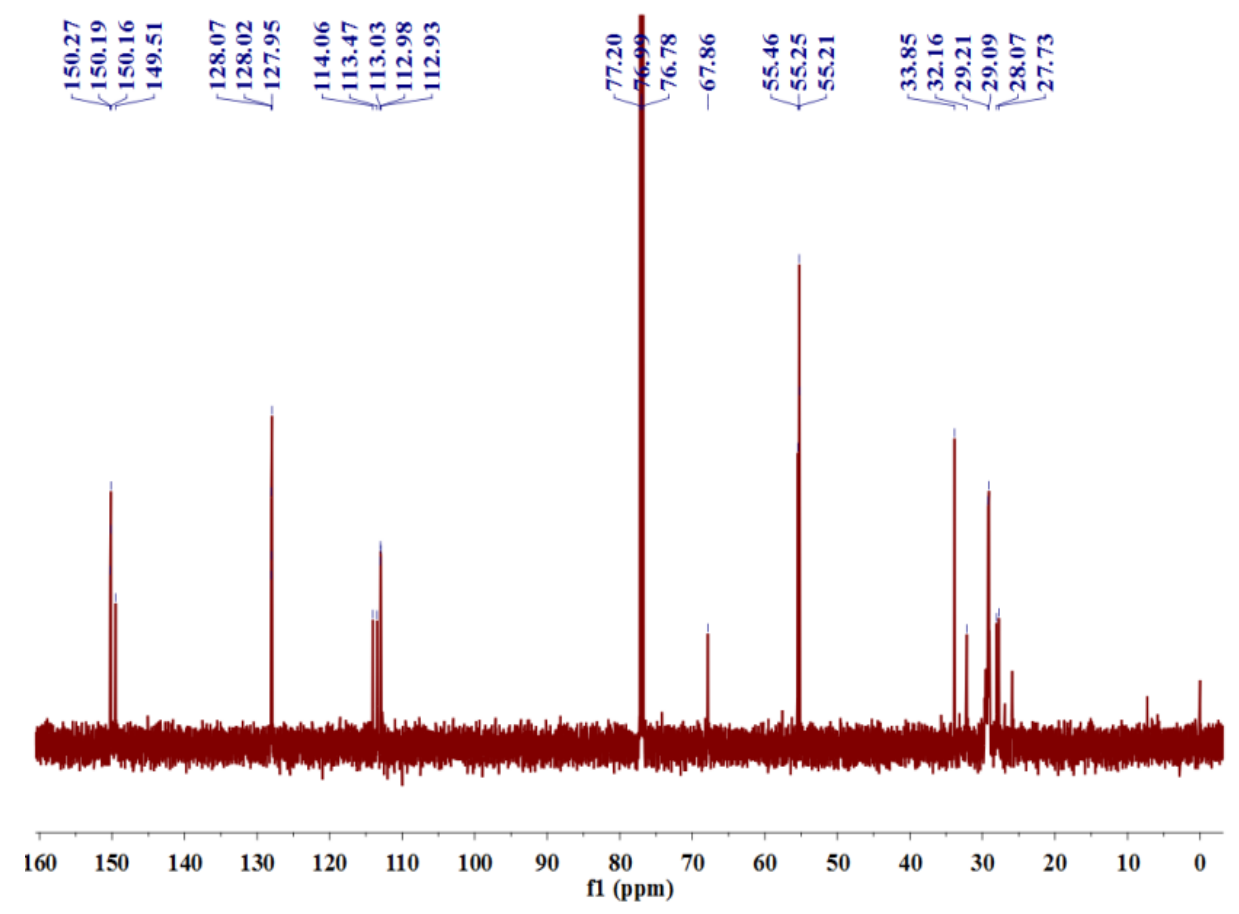

Figure S3. ${ }^{13} \mathrm{C}$ NMR spectrum of compound P5 $\left(\mathrm{CDCl}_{3}, 150 \mathrm{MHz}, 298 \mathrm{~K}\right)$.

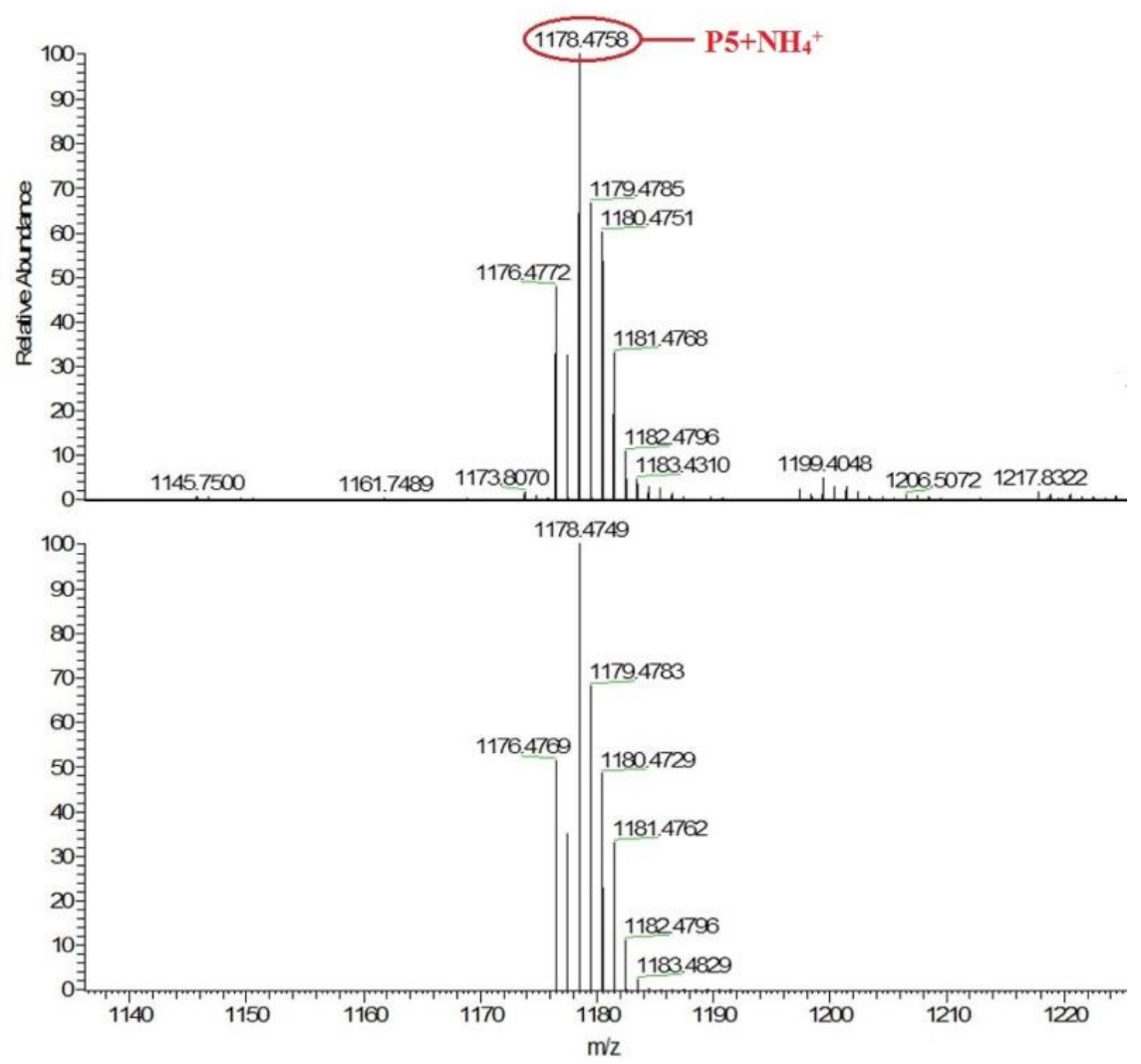

Figure S4. Mass spectrum of P5. 


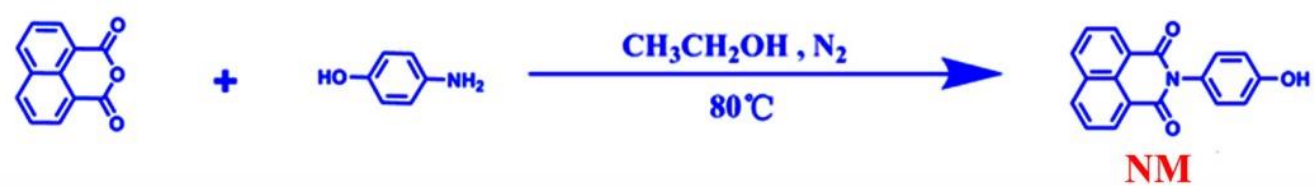

1,8-naphthalic anhydride $(0.19 \mathrm{~g}, 1.0 \mathrm{mmol})$ was added to a mixture of 4-aminophenol $(0.22 \mathrm{~g}$, $2.0 \mathrm{mmol})$ in $\mathrm{C}_{2} \mathrm{H}_{5} \mathrm{OH}(60 \mathrm{~mL})$, and the reaction mixture was stirred reflux $48 \mathrm{~h}$. After reaction was finished, the solvent was filtered under reduced pressure. The crude product was elution with ethanol afforded NM as a white solid $(0.28 \mathrm{~g}, 96 \%)$. Mp: $>290{ }^{\circ} \mathrm{C}$. The proton NMR spectrum of NM is shown in FigureS5. ${ }^{1} \mathrm{H}$ NMR $\left(600 \mathrm{MHz}, \mathrm{DMSO}-d_{6}\right) \delta(\mathrm{ppm}): 9.63(\mathrm{~s}, 1 \mathrm{H}), 8.45-8.44(\mathrm{t}, J=$ $5.2 \mathrm{~Hz}, 4 \mathrm{H}), 7.85(\mathrm{t}, J=5.2 \mathrm{~Hz}, 2 \mathrm{H}), 7.13-7.11(\mathrm{~d}, J=5.6 \mathrm{~Hz}, 2 \mathrm{H}), 6.86-6.85(\mathrm{~d}, J=5.6 \mathrm{~Hz}, 2 \mathrm{H})$. The ${ }^{13} \mathrm{C}$ NMR spectrum of NM is shown in FigureS6. ${ }^{13} \mathrm{C}$ NMR $\left(150 \mathrm{MHz}\right.$, DMSO- $\left.d_{6}\right) \delta(\mathrm{ppm})$ : $164.28,157.55,134.72,130.34,127.32,123.07,115.82$.

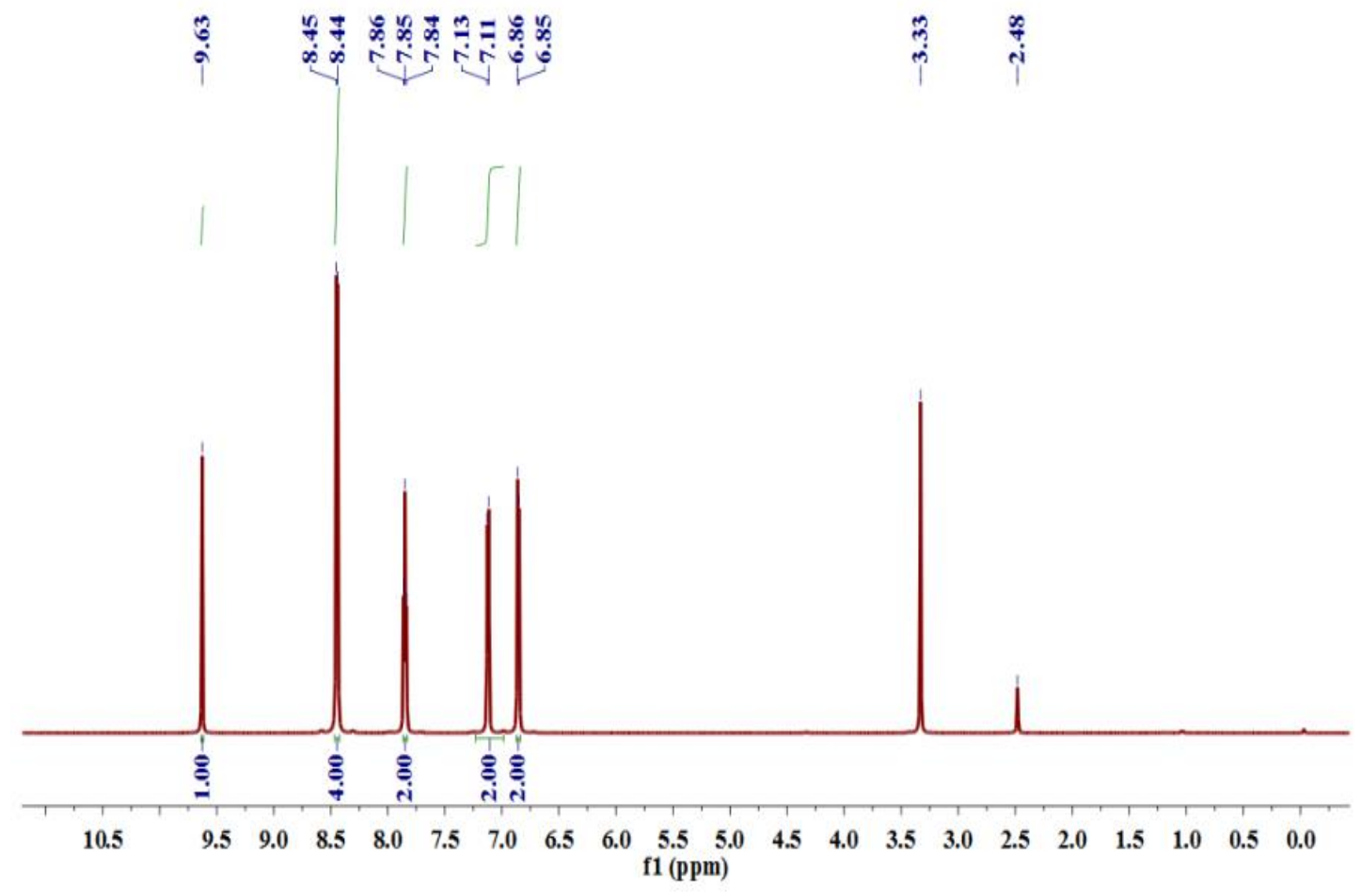

Figure S5. ${ }^{1} \mathrm{H}$ NMR spectrum of compound NM (DMSO- $d_{6}, 600 \mathrm{MHz}, 298 \mathrm{~K}$ ). 


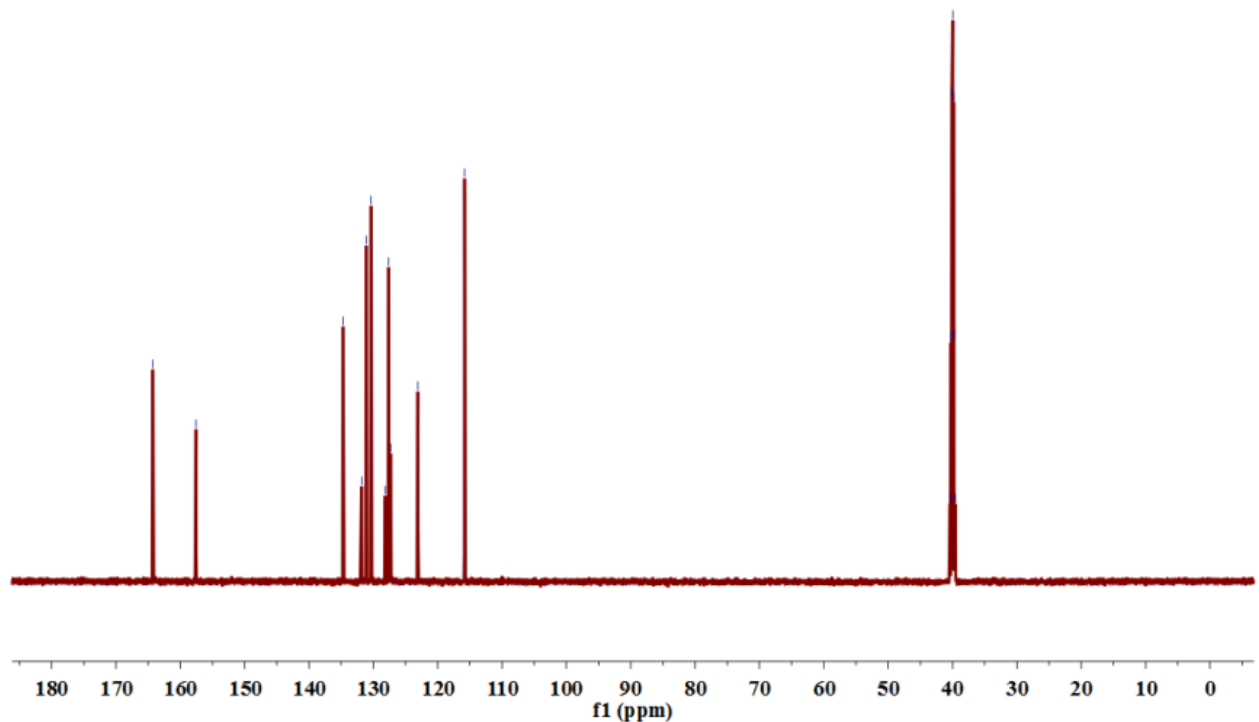

Figure S6. ${ }^{13} \mathrm{C}$ NMR spectrum of compound NM (DMSO- $d_{6}, 150 \mathrm{MHz}, 298 \mathrm{~K}$ ).

Synthesis of P5N:

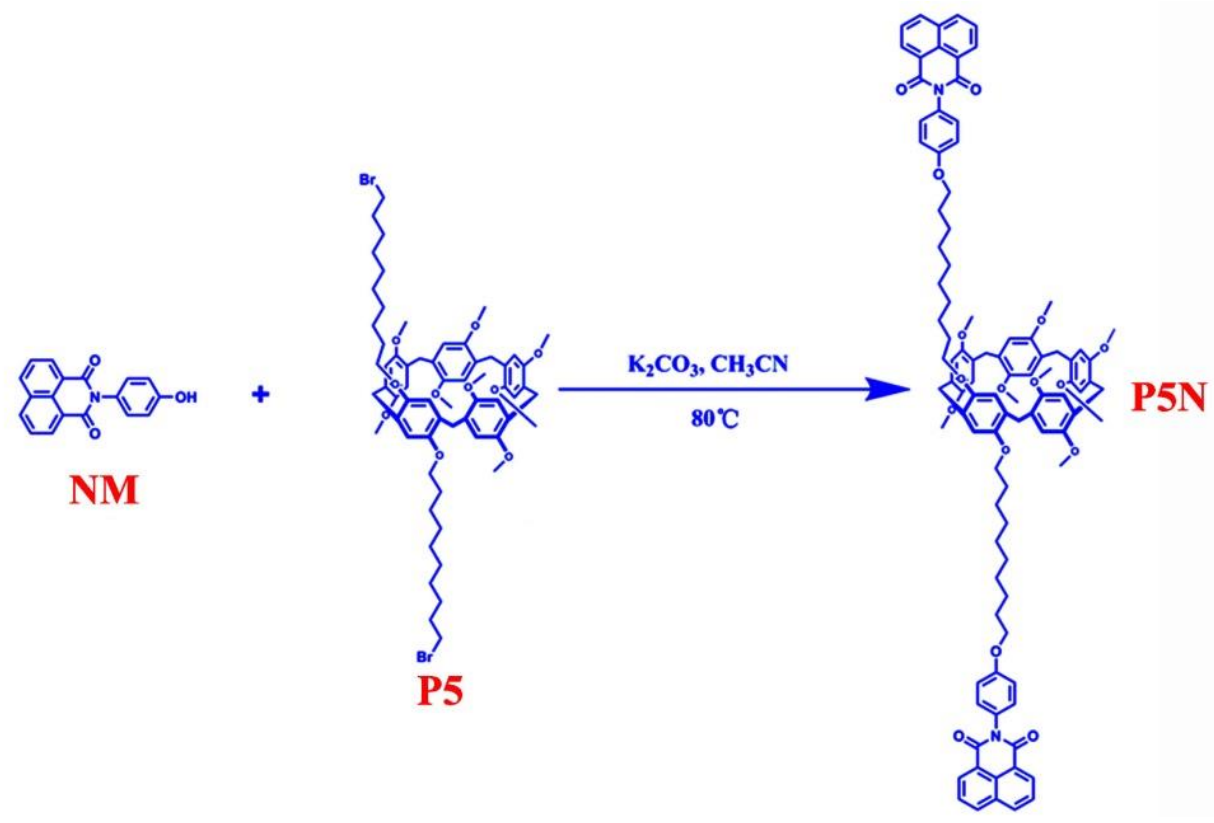

Compound P5 (1.16 g, $1.0 \mathrm{mmol})$ was added to a mixture of compound NM (0.87 g, $3.0 \mathrm{mmol})$, and $\mathrm{K}_{2} \mathrm{CO}_{3}(0.42 \mathrm{~g}, 3.0 \mathrm{mmol})$ in acetonitrile $(50 \mathrm{~mL})$, and the resulting mixture was stirred for $48 \mathrm{~h}$. After reaction was finished, the solvent was evaporated under reduced pressure. The crude product was purified by chromatography on silica gel. Elution with a mixture of dichloromethane/ethyl acetate (v/v, 50:1) afforded P5N as a yellow solid (1.29 g, $82 \%)$. Mp: 102-103 ${ }^{\circ} \mathrm{C}$. The proton NMR spectrum of P5N is shown in FigureS7. ${ }^{1} \mathrm{H}$ NMR $\left(600 \mathrm{MHz}, \mathrm{CDCl}_{3}\right) \delta(\mathrm{ppm}): 8.65(\mathrm{~d}, J=7.2$ 
$\mathrm{Hz}, 4 \mathrm{H}), 8.27-8.26(\mathrm{~d}, J=7.2 \mathrm{~Hz}, 4 \mathrm{H}), 7.79(\mathrm{t}, J=7.6 \mathrm{~Hz}, 4 \mathrm{H}), 7.22-7.21(\mathrm{~d}, J=8.7 \mathrm{~Hz}, 4 \mathrm{H})$, 7.03-7.02 (d, $J=8.7 \mathrm{~Hz}, 4 \mathrm{H}), 6.87-6.80(\mathrm{~m}, 10 \mathrm{H}), 3.91-3.86(\mathrm{~m}, 8 \mathrm{H}), 3.82-3.72(\mathrm{~m}, 10 \mathrm{H}), 3.72-3.69$ $(\mathrm{m}, 24 \mathrm{H}), 1.82-1.76(\mathrm{~m}, 3 \mathrm{H}), 1.54-1.21(\mathrm{~m}, 19 \mathrm{H}), 1.05(\mathrm{~s}, 3 \mathrm{H}), 0.89-0.85(\mathrm{~m}, 7 \mathrm{H})$. The ${ }^{13} \mathrm{C}$ NMR spectrum of P5N is shown in FigureS8. ${ }^{13} \mathrm{C} \mathrm{NMR}\left(150 \mathrm{MHz}, \mathrm{CDCl}_{3}\right) \delta(\mathrm{ppm}): 164.56,159.20$, 150.65, 134.16, 131.73, 131.55, 129.43, 128.10, 126.99, 122.91, 115.11, 68.29, 55.71, 55.68, 55.55, 29.08, 29.03. ESI-MS is shown in FigureS9: m/z $[\mathrm{M}]^{+}$calcd. for $\mathrm{C}_{99} \mathrm{H}_{104} \mathrm{~N}_{2} \mathrm{O}_{16}$ 1577.7419, found 1577.7498 .

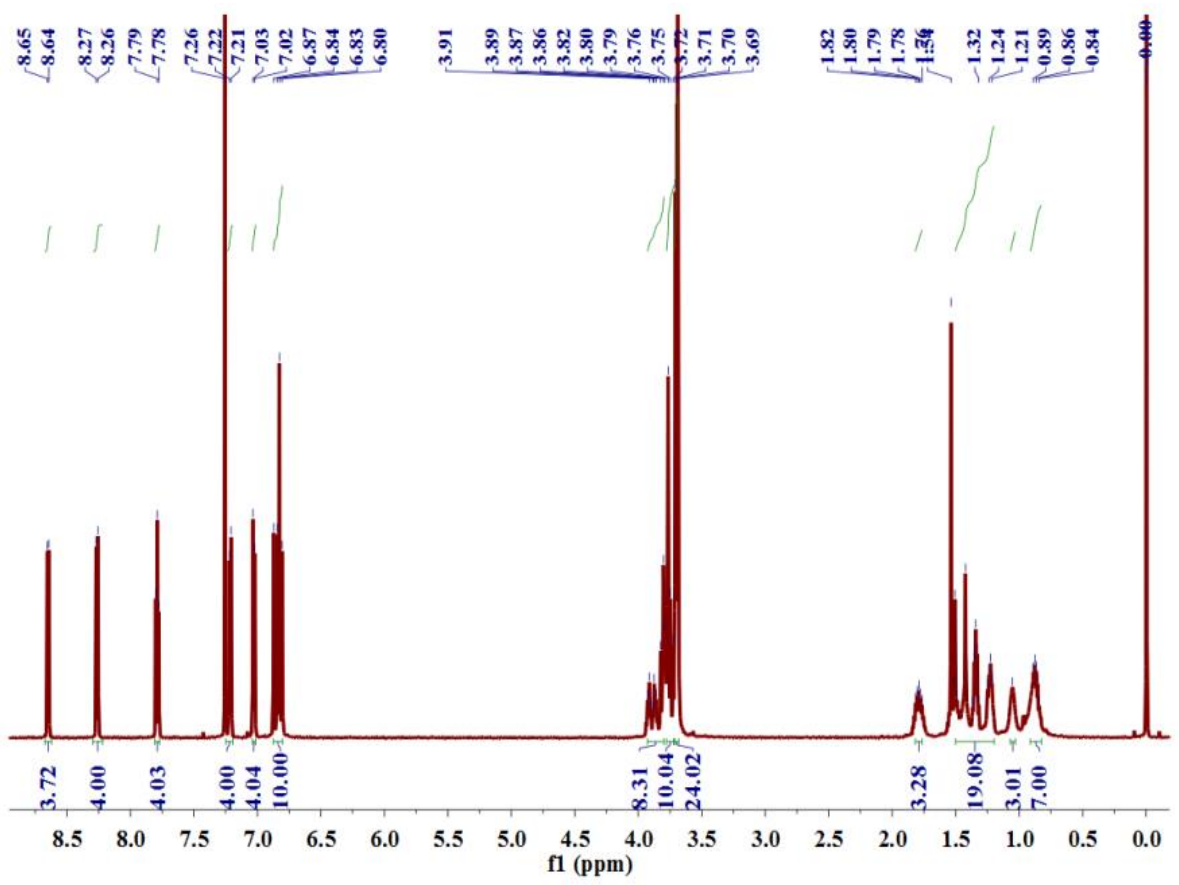

Figure S7. ${ }^{1} \mathrm{H}$ NMR spectrum of compound P5N $\left(\mathrm{CDCl}_{3}, 600 \mathrm{MHz}, 298 \mathrm{~K}\right)$.
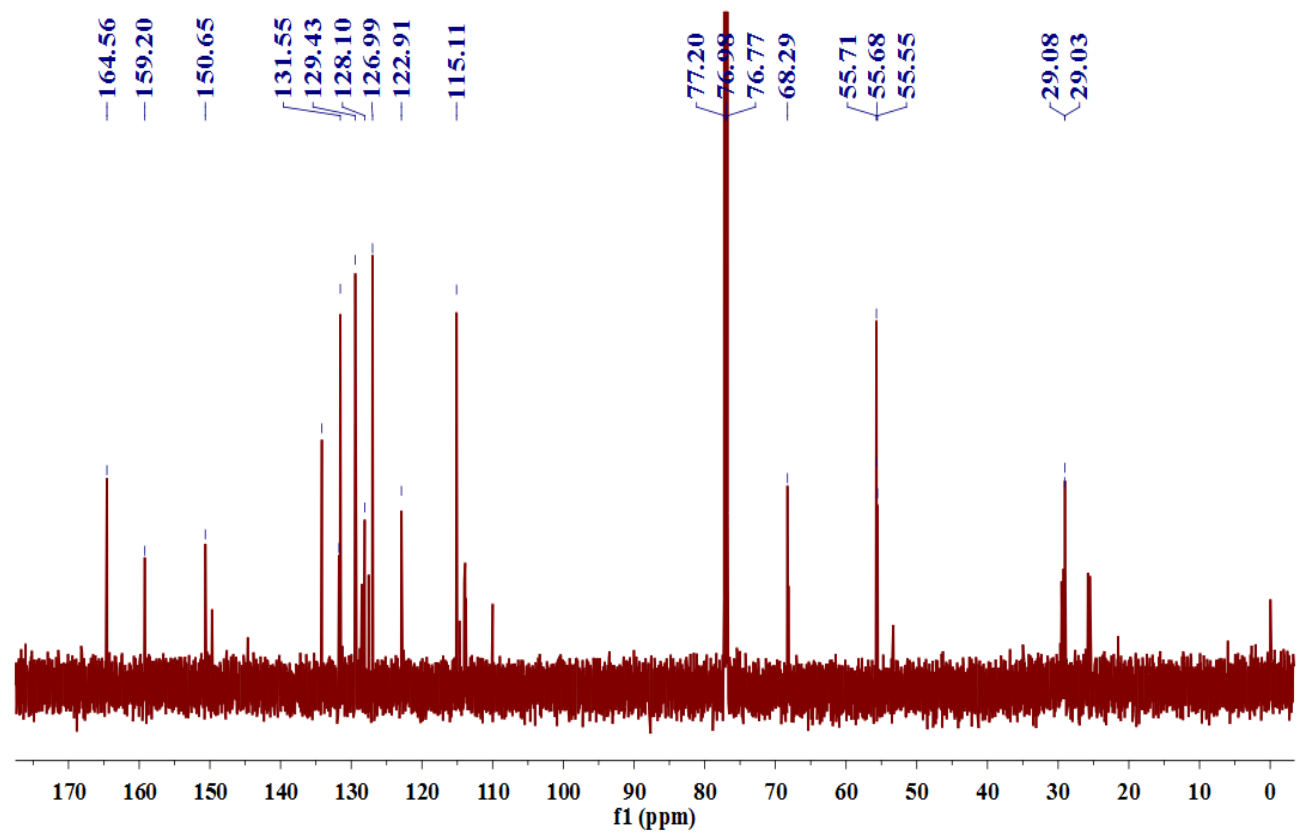

Figure S8. ${ }^{13} \mathrm{C}$ NMR spectrum of compound P5N $\left(\mathrm{CDCl}_{3}, 150 \mathrm{MHz}, 298 \mathrm{~K}\right)$. 


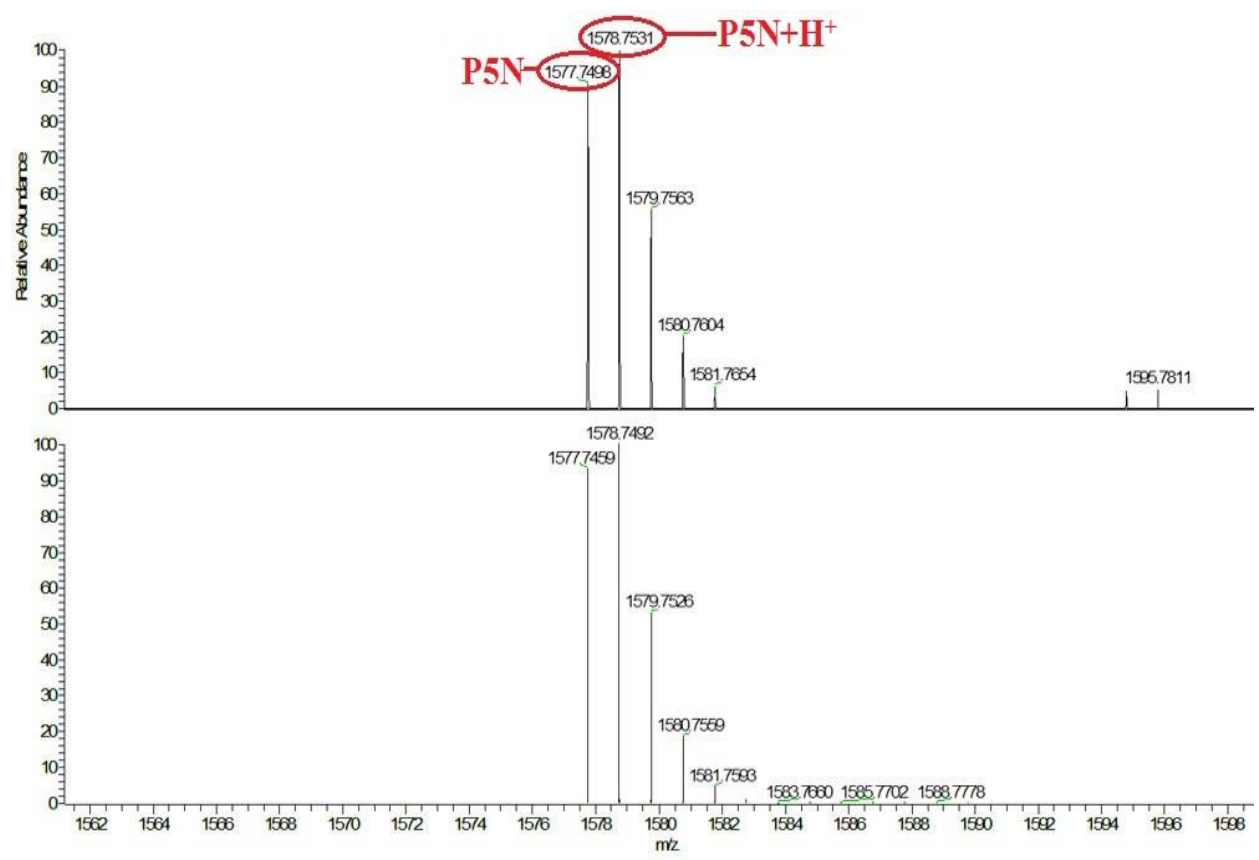

Figure S9. Mass spectrum of P5N.

Synthesis of compound $\boldsymbol{G}$ :

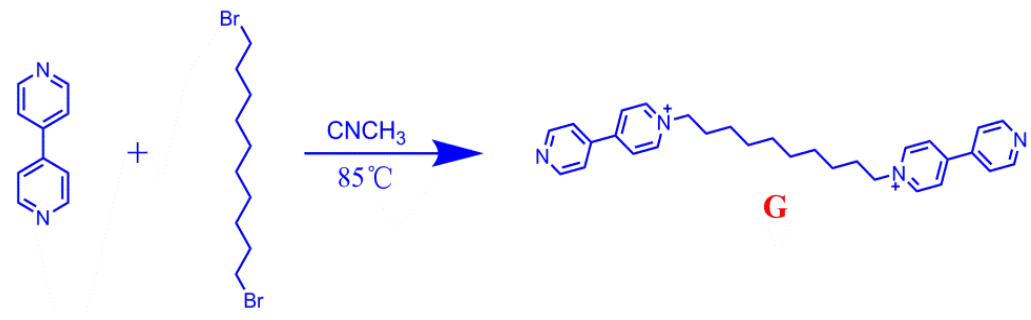

A solution of 1,10-dibromodecane $(1.89 \mathrm{~g}, 6.3 \mathrm{mmol})$ in $\mathrm{CH}_{3} \mathrm{CN}(25 \mathrm{~mL})$ was added dropwise into a stirred solution of 4,4'-bipyridine (5.56 g, $35.7 \mathrm{mmol})$ in $\mathrm{CH}_{3} \mathrm{CN}$ (50 mL) and refluxed over night. After it cooled, the suspension was filtered. The solid was washed with $\mathrm{CH}_{3} \mathrm{CN}$ and then dried in an oven to afford a pale green solid G (3.3 g, 86\%). ${ }^{1} \mathrm{H}$ NMR (400 MHz, DMSO- $\left.d_{6}\right) \delta 9.37$ (d, $J=6.7 \mathrm{~Hz}, 4 \mathrm{H}), 8.89(\mathrm{~d}, J=6.7 \mathrm{~Hz}, 4 \mathrm{H}), 8.71(\mathrm{~d}, J=6.7 \mathrm{~Hz}, 4 \mathrm{H}), 8.10(\mathrm{~d}, J=6.1 \mathrm{~Hz}, 4 \mathrm{H}), 4.72(\mathrm{t}$, $J=7.3 \mathrm{~Hz}, 4 \mathrm{H}), 1.97(\mathrm{~s}, 4 \mathrm{H}), 1.32(\mathrm{~d}, J=15.5 \mathrm{~Hz}, 12 \mathrm{H})$. 


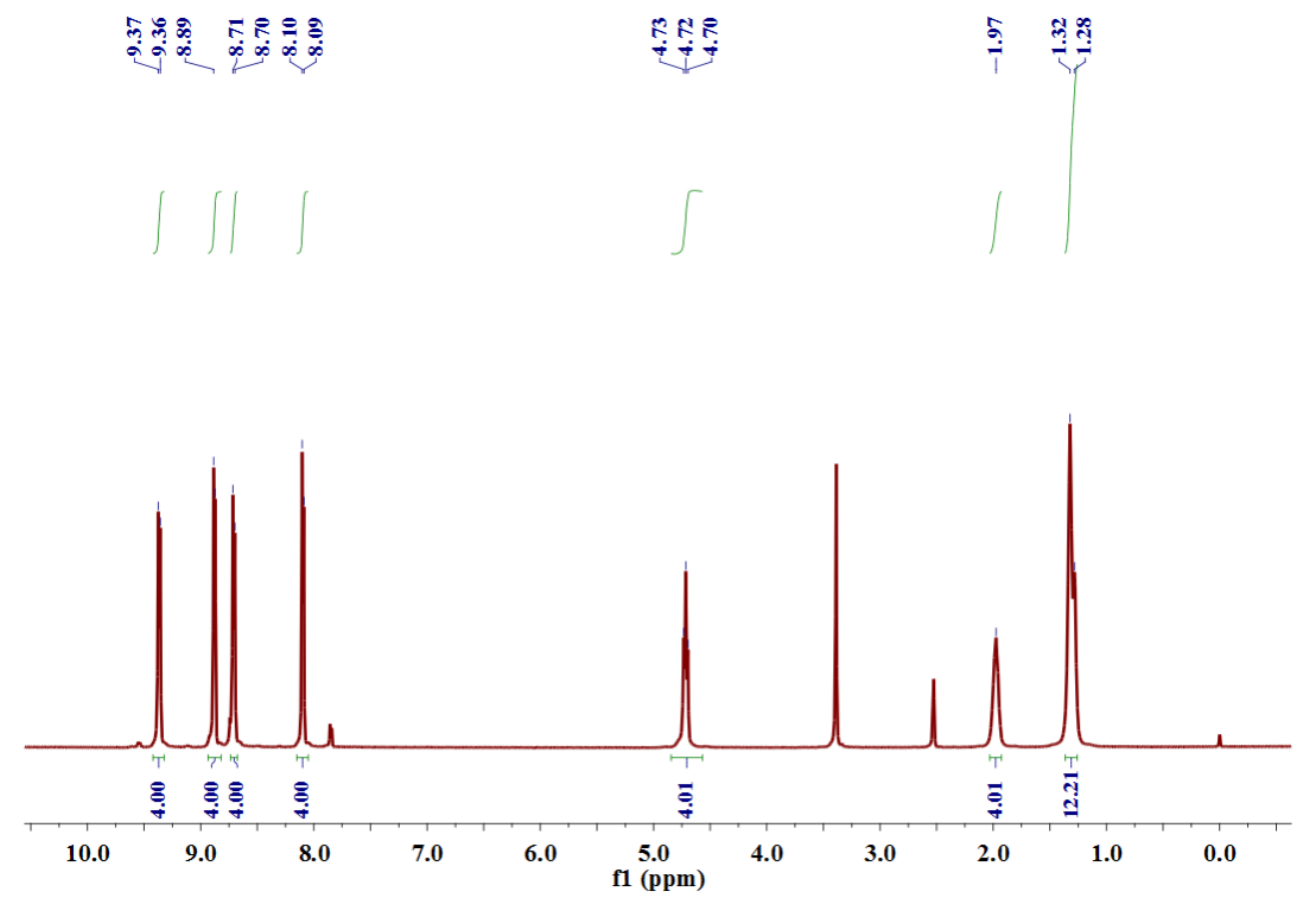

Figure S10. ${ }^{1} \mathrm{H}$ NMR spectrum of $\mathbf{G}$ (DMSO- $d_{6}, 600 \mathrm{MHz}, 298 \mathrm{~K}$ ). 
Table S1. Gelation property of SPN-TDPG.

\begin{tabular}{|c|c|c|c|c|}
\hline Entry & Solvent & State & $\mathrm{CGC}(\%)$ & $\mathrm{T}_{\mathrm{gel}}\left({ }^{\circ} \mathrm{C}, \mathrm{wt} \%\right)$ \\
\hline 1 & Ethyl acetate & $\mathrm{S}$ & 1 & 1 \\
\hline 2 & Ethyl alcohol & $\mathrm{P}$ & 1 & 1 \\
\hline 3 & $\mathrm{CCl}_{4}$ & $\mathrm{P}$ & 1 & 1 \\
\hline 4 & PEG-400 & $\mathrm{P}$ & 1 & 1 \\
\hline 5 & Isopropyl alcohol & $\mathrm{P}$ & 1 & 1 \\
\hline 6 & Ethylene glycol & $\mathrm{P}$ & 1 & 1 \\
\hline 7 & Acetone & $\mathrm{P}$ & 1 & 1 \\
\hline 8 & DMF & S & 1 & 1 \\
\hline 9 & $\mathrm{DMF} / \mathrm{H}_{2} \mathrm{O}(\mathrm{V} / \mathrm{V}=9: 1)$ & G & $9.5 \%$ & $45 \sim 48{ }^{\circ} \mathrm{C}$ \\
\hline 10 & DMSO & S & 1 & 1 \\
\hline 11 & $\mathrm{DMSO} / \mathrm{H}_{2} \mathrm{O}(\mathrm{V} / \mathrm{V}=8: 2)$ & G & $10.0 \%$ & $61 \sim 63{ }^{\circ} \mathrm{C}$ \\
\hline 12 & n-Propyl Alcohol & $\mathrm{P}$ & 1 & 1 \\
\hline 13 & Methyl alcohol & $\mathrm{P}$ & 1 & 1 \\
\hline 14 & Tert-butyl alcohol & $\mathrm{P}$ & 1 & 1 \\
\hline 15 & Glycerol & $\mathrm{P}$ & 1 & \\
\hline 16 & Isoamyl alcohol & $\mathrm{P}$ & 1 & 1 \\
\hline 17 & n-Butyl alcohol & $\mathrm{P}$ & 1 & 1 \\
\hline 18 & Cyclohexanol & $\mathrm{G}$ & $2.0 \%$ & $55 \sim 58^{\circ} \mathrm{C}$ \\
\hline 19 & N-hexanol & $\mathrm{G}$ & $3.0 \%$ & $50 \sim 52{ }^{\circ} \mathrm{C}$ \\
\hline 19 & $\mathrm{CH}_{2} \mathrm{Cl}_{2}$ & $\mathrm{P}$ & 1 & 1 \\
\hline 20 & Tetrahydrofuran & $S$ & 1 & 1 \\
\hline 21 & Acetic acid & $\mathrm{P}$ & 1 & 1 \\
\hline 22 & n-Butanol & $\mathrm{P}$ & 1 & 1 \\
\hline 23 & Cyclohexane & $\mathrm{P}$ & 1 & 1 \\
\hline
\end{tabular}

State: $\quad 10 \mathrm{mg} / \mathrm{mL}=1 \%, \mathrm{G}=$ Gelation, $\mathrm{S}=$ Solution, $\mathrm{P}=$ Precipitation. 


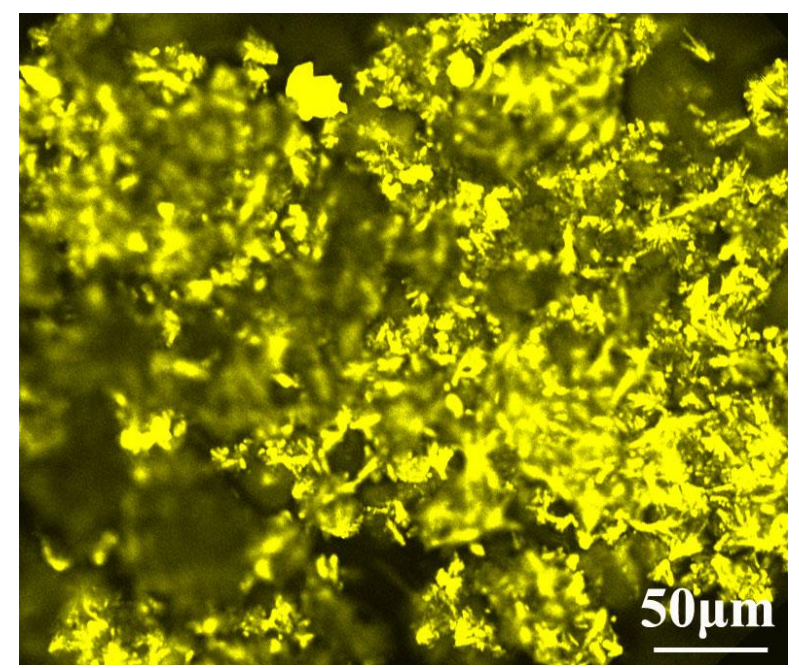

Figure S11. LSCM images of SPN-TDPG xerogel.

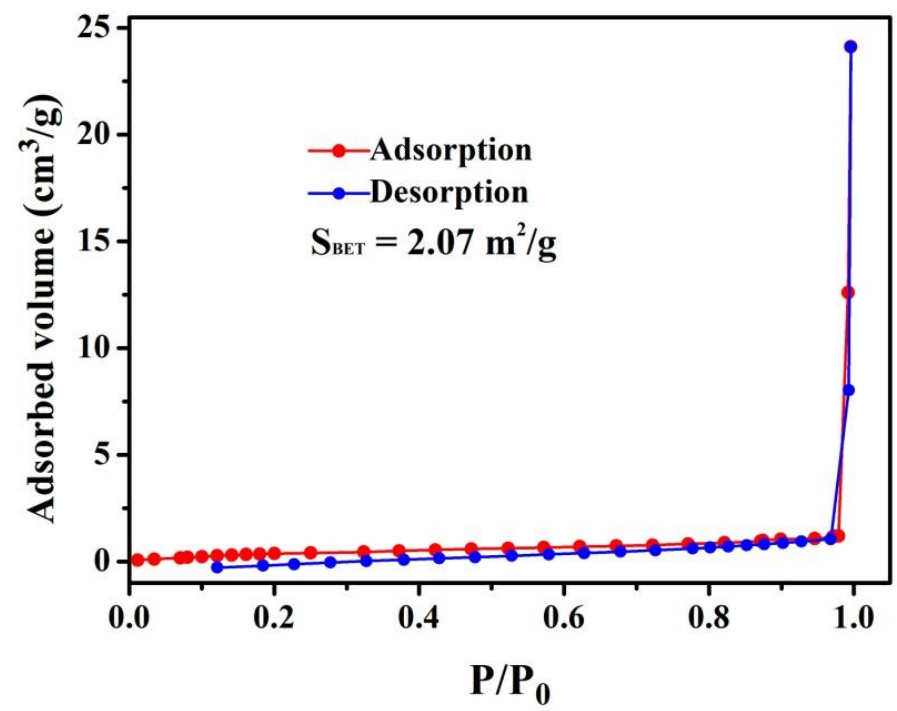

Figure S12. Nitrogen adsorption-desorption isotherm (77.0 K) of SPN-TDPG.

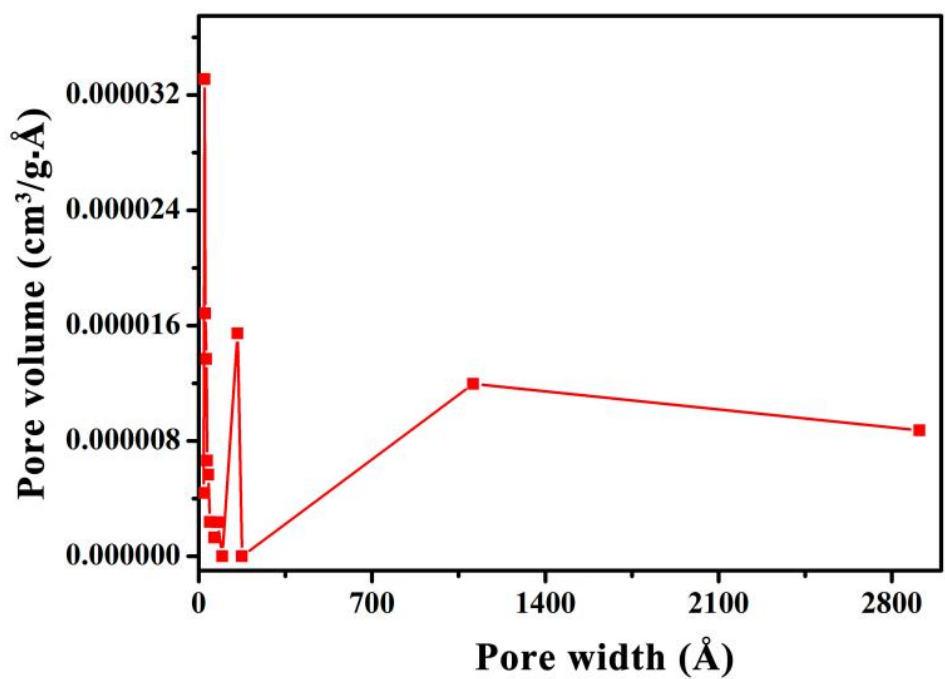

Figure S13 Pore size distribution profiles of SPN-TDPG. 


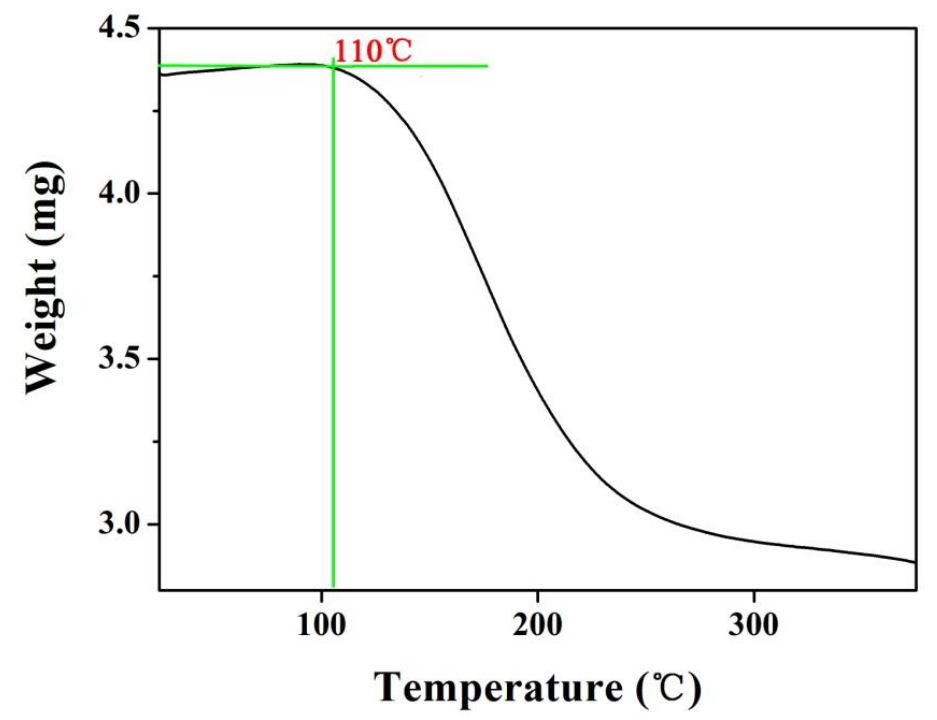

Figure S14. Thermogravimetric analysis of SPN-TDPG.

Table S2. Water regain analysis of SPN-TDPG. The water regain (expressed as weight percent) of the SPN-TDPG was determined from the average (87.4\%) of three measurements.

\begin{tabular}{cccc}
\hline Entry & $M_{d}(\mathrm{mg})$ & $M_{w}(\mathrm{mg})$ & Water regain \% \\
\hline 1 & 30.1 & 56.3 & 87.0 \\
2 & 29.8 & 55.8 & 87.2 \\
3 & 30.6 & 57.5 & 87.9 \\
\hline
\end{tabular}




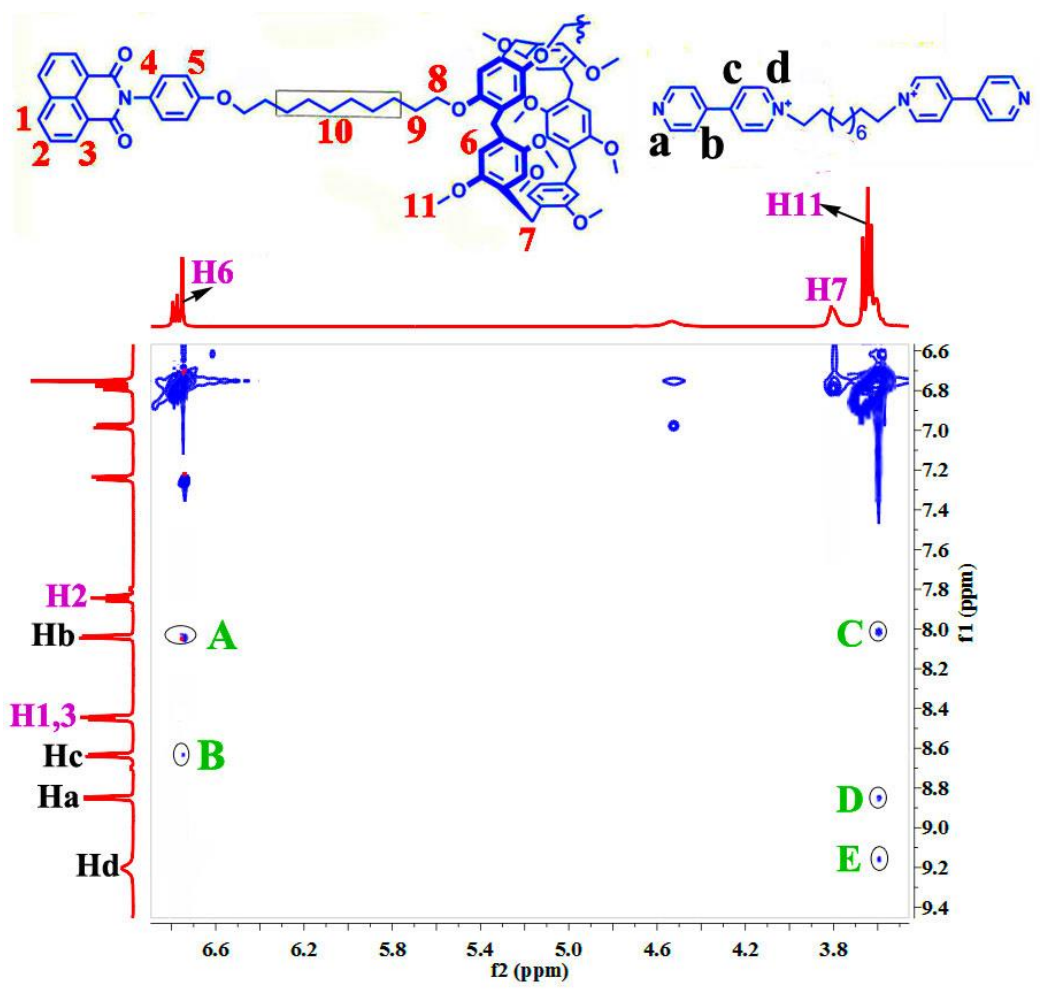

Figure S15. Partial 2D NOESY NMR spectrum of 5.0 mM P5N and G in DMSO- $d_{6}$ solution (600 $\mathrm{MHz}, 298 \mathrm{~K})$.

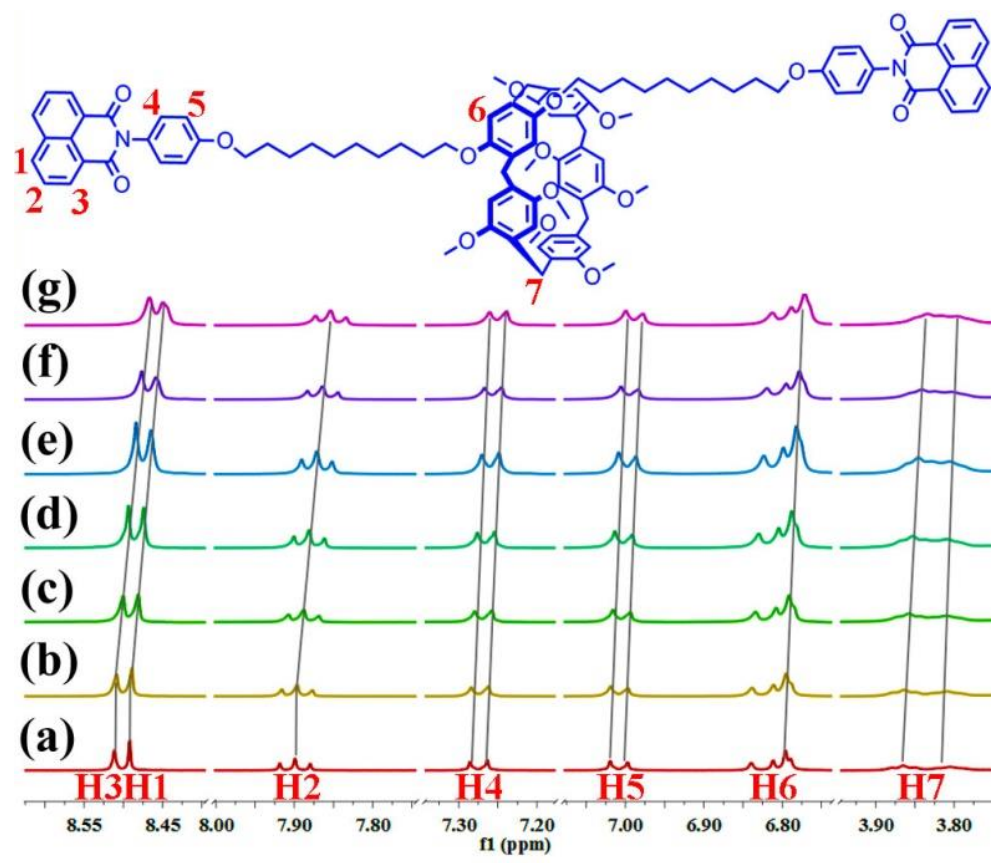

Figure S16. Partial ${ }^{1} \mathrm{H}$ NMR spectra $(600 \mathrm{MHz}, 298 \mathrm{~K})$ of $\mathbf{P 5 N}$ in DMSO- $d_{6}$ at various concentrations: (a) $1.0 \mathrm{mM}$; (b) $2.0 \mathrm{mM}$; (c) $5.0 \mathrm{mM}$; (d) $10.0 \mathrm{mM}$; (e) $15.0 \mathrm{mM}$; (f) $20.0 \mathrm{mM}$; (g) $30.0 \mathrm{mM}$. 


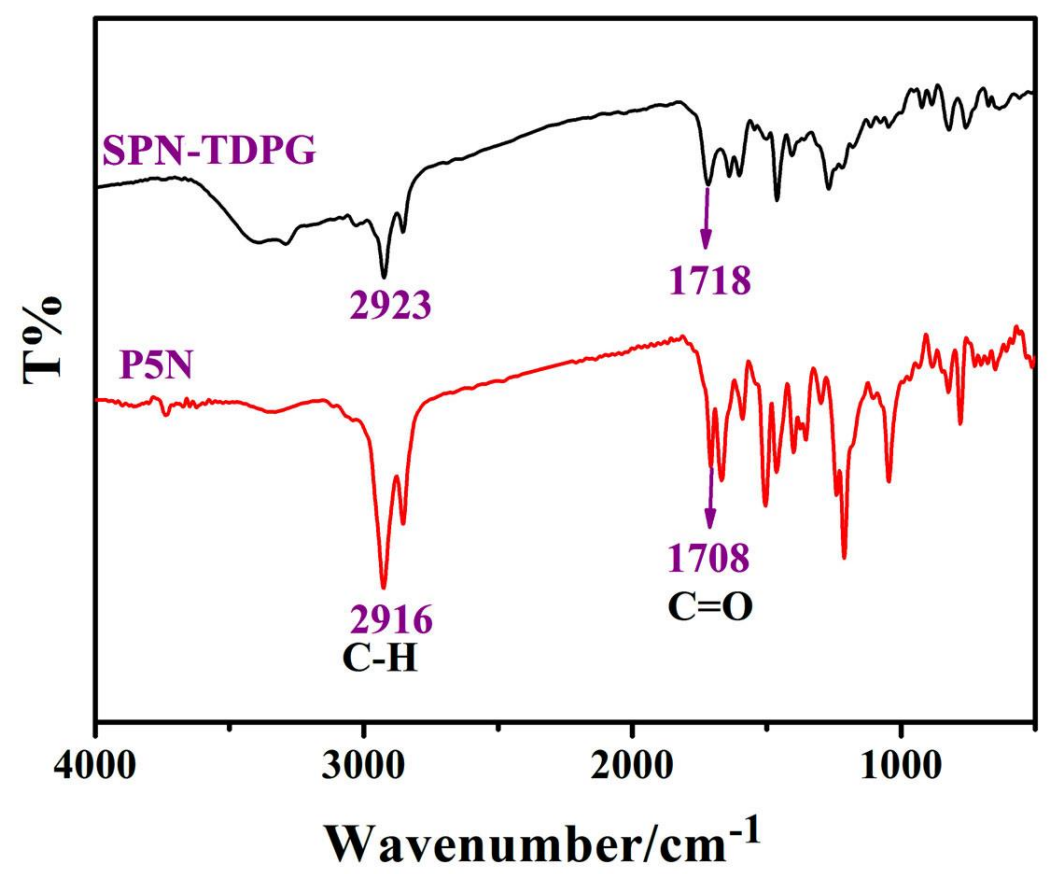

Figure S17. FT-IR spectra of powdered P5N, xerogel SPN-TDPG.

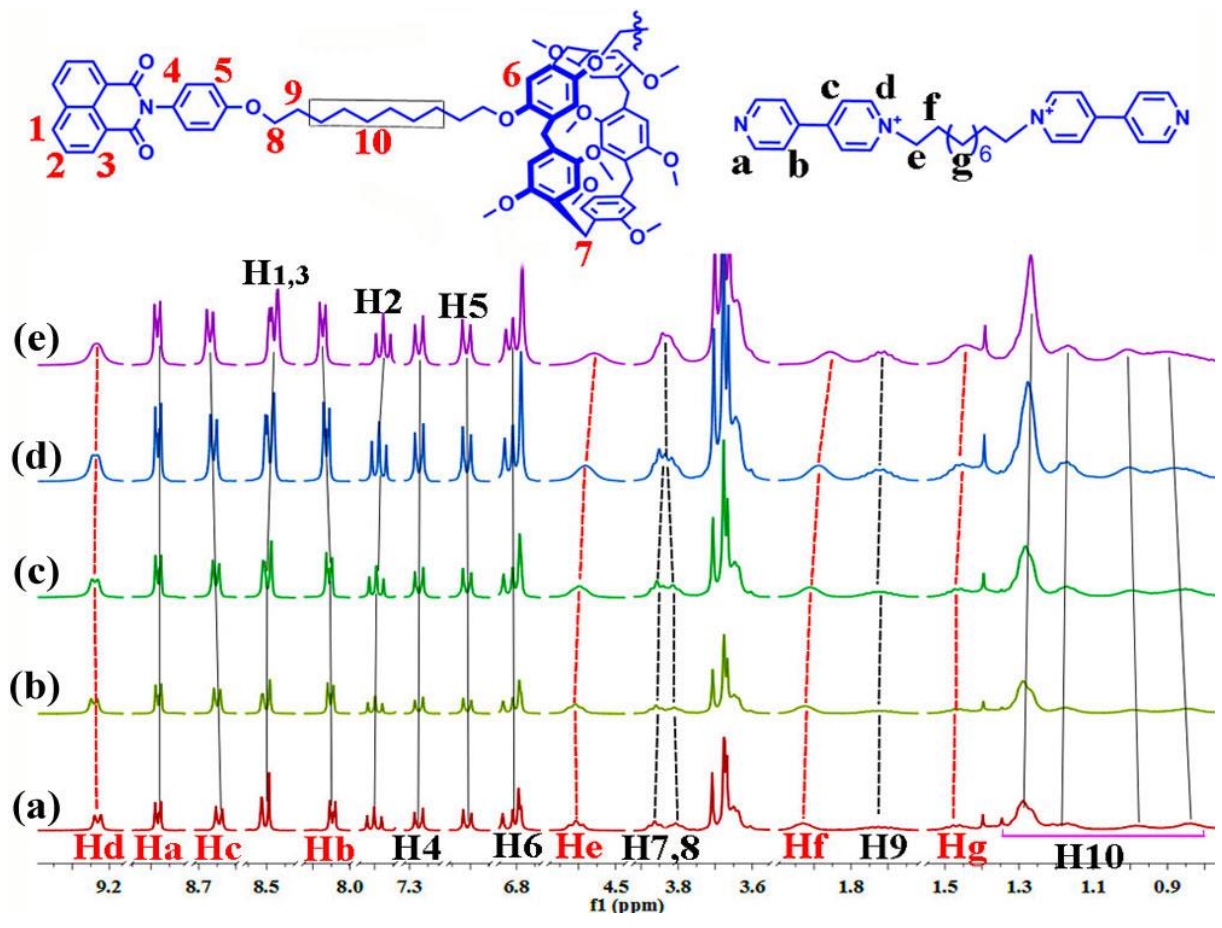

Figure S18. Partial ${ }^{1} \mathrm{H}$ NMR spectra $\left(600 \mathrm{MHz}, \mathrm{DMSO}-d_{6}, 298 \mathrm{~K}\right)$ of $\mathbf{P 5 N}$ and $\mathbf{G}$ at different concentrations: (a) $5.0 \mathrm{mM}$; (b) $10.0 \mathrm{mM}$; (c) $20.0 \mathrm{mM}$; (d) $40.0 \mathrm{mM}$; (e) $80.0 \mathrm{mM}$. 

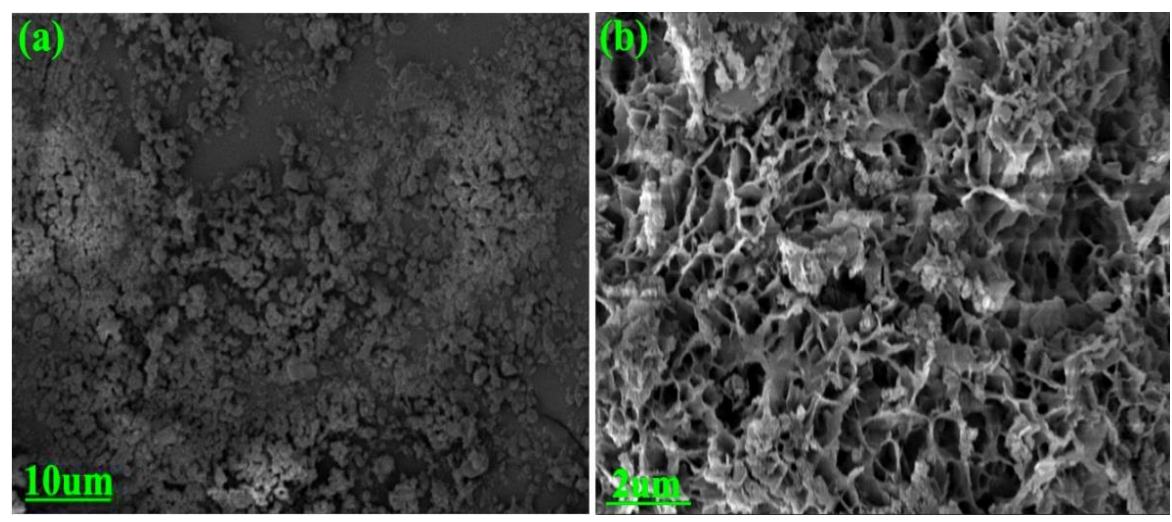

Figure S19. Representative SEM images showing the morphology of (a) P5N and (b) SPN-TDPG.

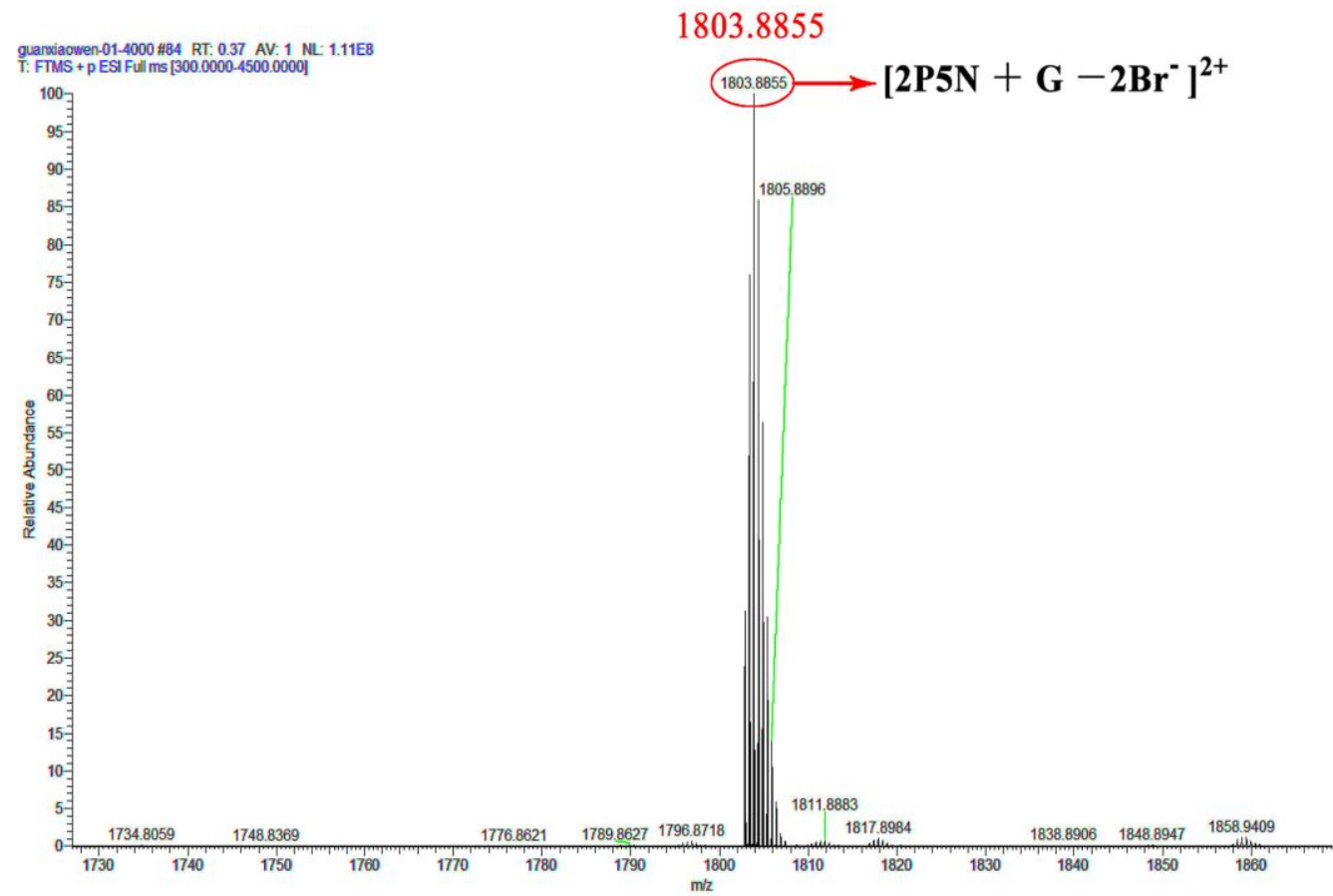

Figure S20. HR-ESI-MS of mixture P5N and G, clearly indicating the 2:1 stoichiometry for P5N and $\mathbf{G}$. 

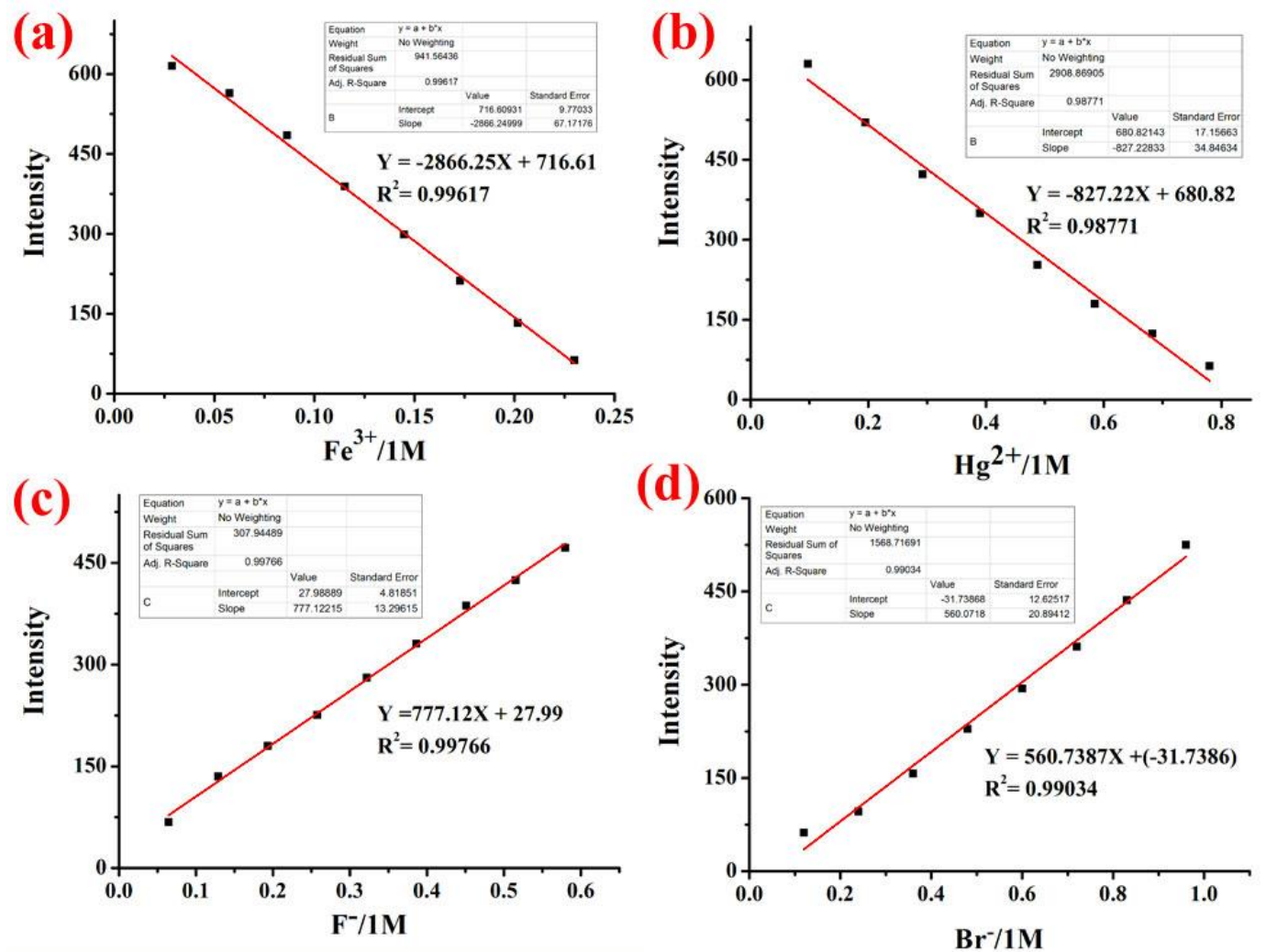

Figure S21. The linear range of (a) SPN-TDPG for $\mathrm{Fe}^{3+}$; (b) SPN-TDPG for $\mathrm{Hg}^{2+}$; (c) SPN-TDPG-Fe for $\mathrm{F}^{-}$; (d) SPN-TDPG-Hg for $\mathrm{Br}^{-}$.

Table S3. Limits of detection the SPN-TDPG or SPN-TDPG treated by metal ions for target ions.

\begin{tabular}{cccc}
\hline Entry & Gel & Target ions & LOD/M \\
\hline 1 & SPN-TDPG & $\mathrm{Fe}^{3+}$ & $9.19 \times 10^{-9}$ \\
2 & SPN-TDPG & $\mathrm{Hg}^{2+}$ & $3.95 \times 10^{-8}$ \\
3 & SPN-TDPG-Fe & $\mathrm{F}^{-}$ & $3.38 \times 10^{-8}$ \\
4 & SPN-TDPG-Hg & $\mathrm{Br}^{-}$ & $8.17 \times 10^{-8}$ \\
\hline
\end{tabular}




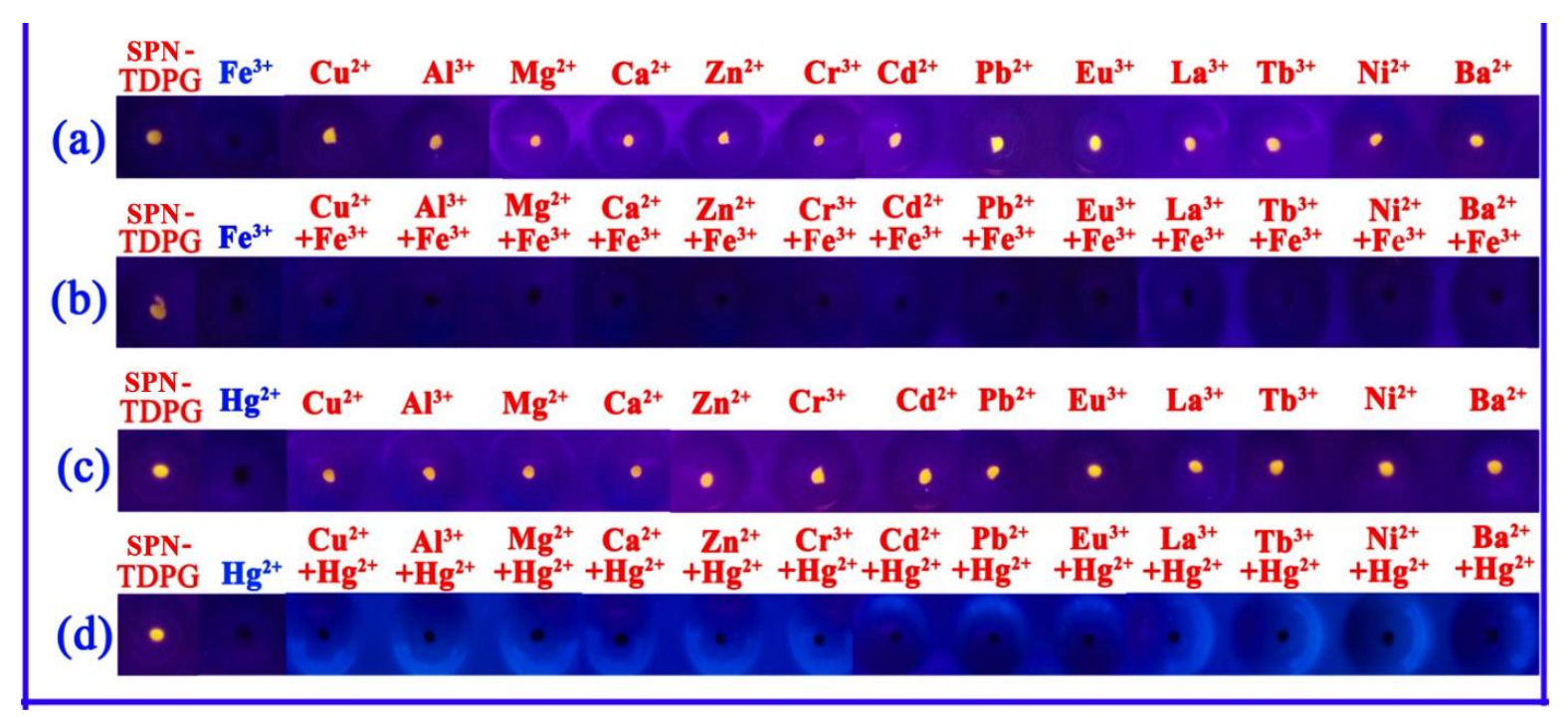

Figure S22. The control experiments: (a) SPN-TDPG treated by water solutions of various cations; (b) SPN-TDPG contained water solutions of various cations treated by water solution of $\mathrm{Fe}^{3+}$; (c) SPN-TDPG treated by water solutions of various cations; (d) SPN-TDPG contained water solutions of various cations treated by water solution of $\mathrm{Hg}^{2+}$.
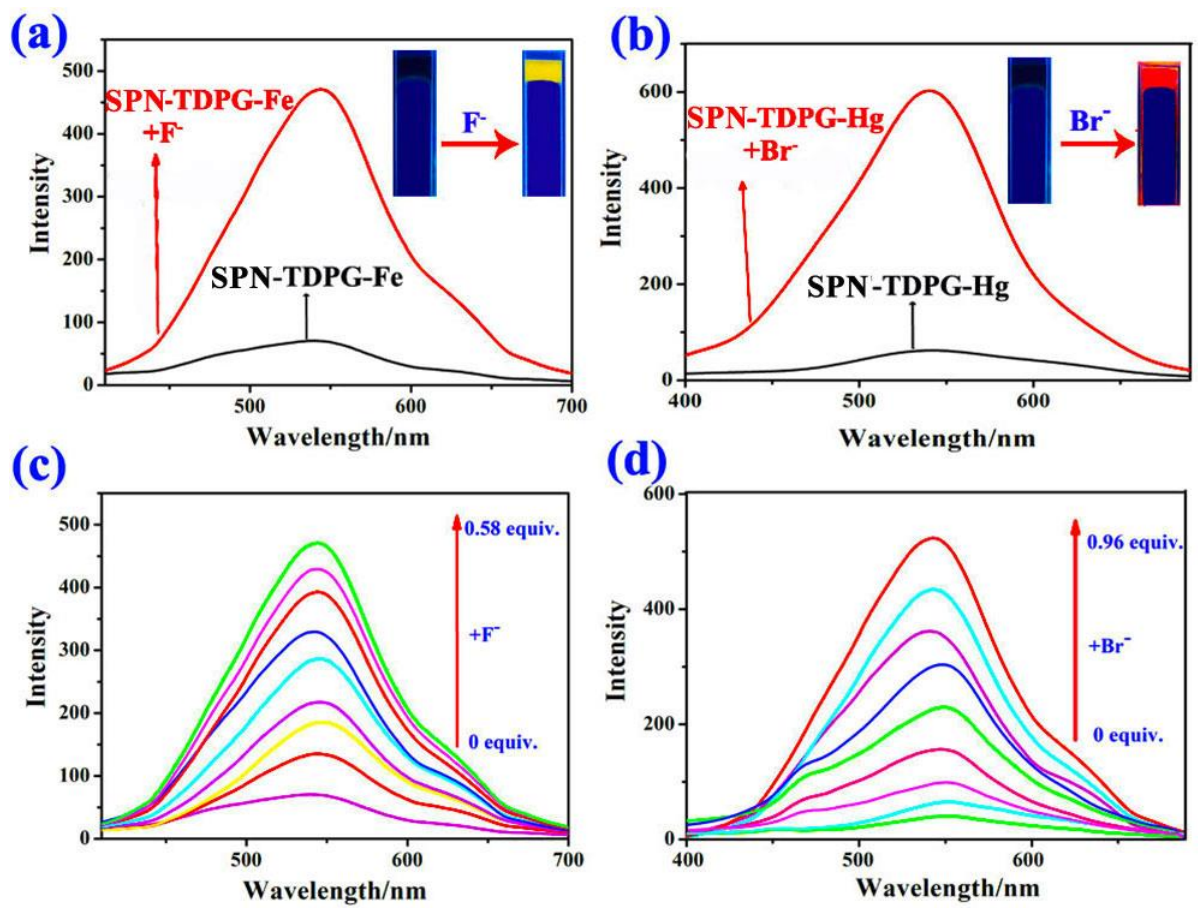

Figure S23. Fluorescence spectra of supramolecular gel (in gelated state) (a) SPN-TDPG-Fe and SPN-TDPG-Fe + F- ; (b) SPN-TDPG-Hg and SPN-TDPG-Hg + $\mathrm{Br}^{-}$; (c) The fluorescent titrations of SPN-TDPG-Fe for $\mathrm{F}^{-}$; (d) The fluorescent titrations of SPN-TDPG-Hg for Br- 


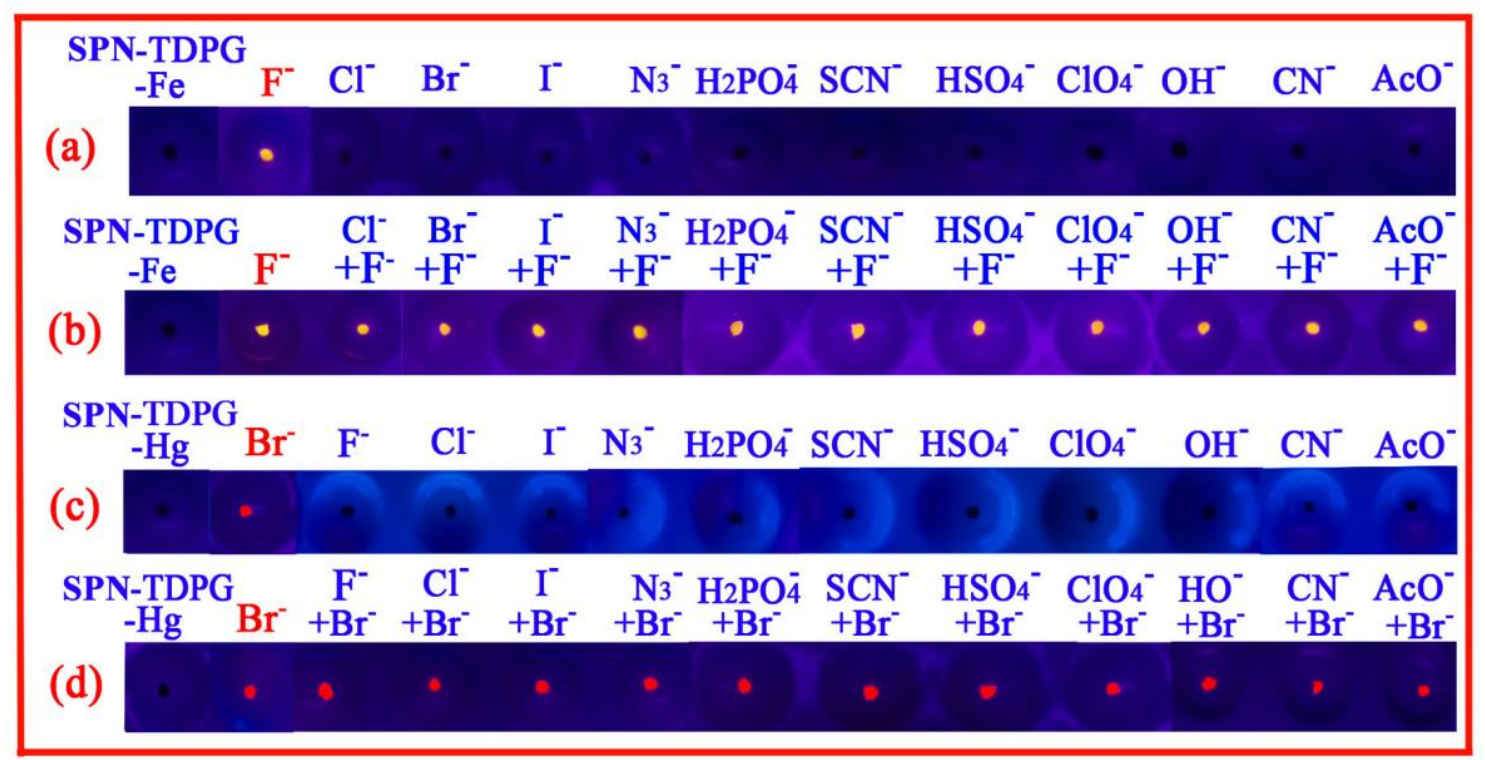

Figure S24. The control experiments: (a) SPN-TDPG-Fe and SPN-TDPG-Fe treated by water solutions of various anions; (b) SPN-TDPG-Fe and SPN-TDPG-Fe contained water solutions of various anions treated by water solution of $\mathrm{F}^{-}$. (c) SPN-TDPG-Hg and SPN-TDPG-Hg treated by water solutions of various anions; (d) SPN-TDPG-Hg and SPN-TDPG-Hg contained water solutions of various anions treated by water solution of $\mathrm{Br}^{-}$. 
Table S4. Chemical name, chemical structures and exact weight of pollutants.

\begin{tabular}{|c|c|c|c|}
\hline Entry & Chemical name & Chemical structures & Molar mass $(\mathrm{g} / \mathrm{mol})$ \\
\hline 1 & Methylene Blue & & 319.09 \\
\hline 2 & Bismarck Brown Y & & 346.16 \\
\hline 3 & Giemsa's Stain & & 291.06 \\
\hline 4 & Orangel I & & 350.03 \\
\hline 5 & Methyl Orangel & & 327.06 \\
\hline 6 & Rhodamine B & & 481.03 \\
\hline 7 & Sudan I & & 248.28 \\
\hline 8 & Sudan II & & 276.33 \\
\hline 9 & Picric Acid & & 229.10 \\
\hline 10 & 1-Naphthol & & 144.17 \\
\hline 11 & Potassium Permanganate & $\mathrm{KMnO}_{4}$ & 158.03 \\
\hline 12 & Potassium Dichromate & $\mathrm{K}_{2} \mathrm{Cr}_{2} \mathrm{O}_{7}$ & 294.18 \\
\hline
\end{tabular}



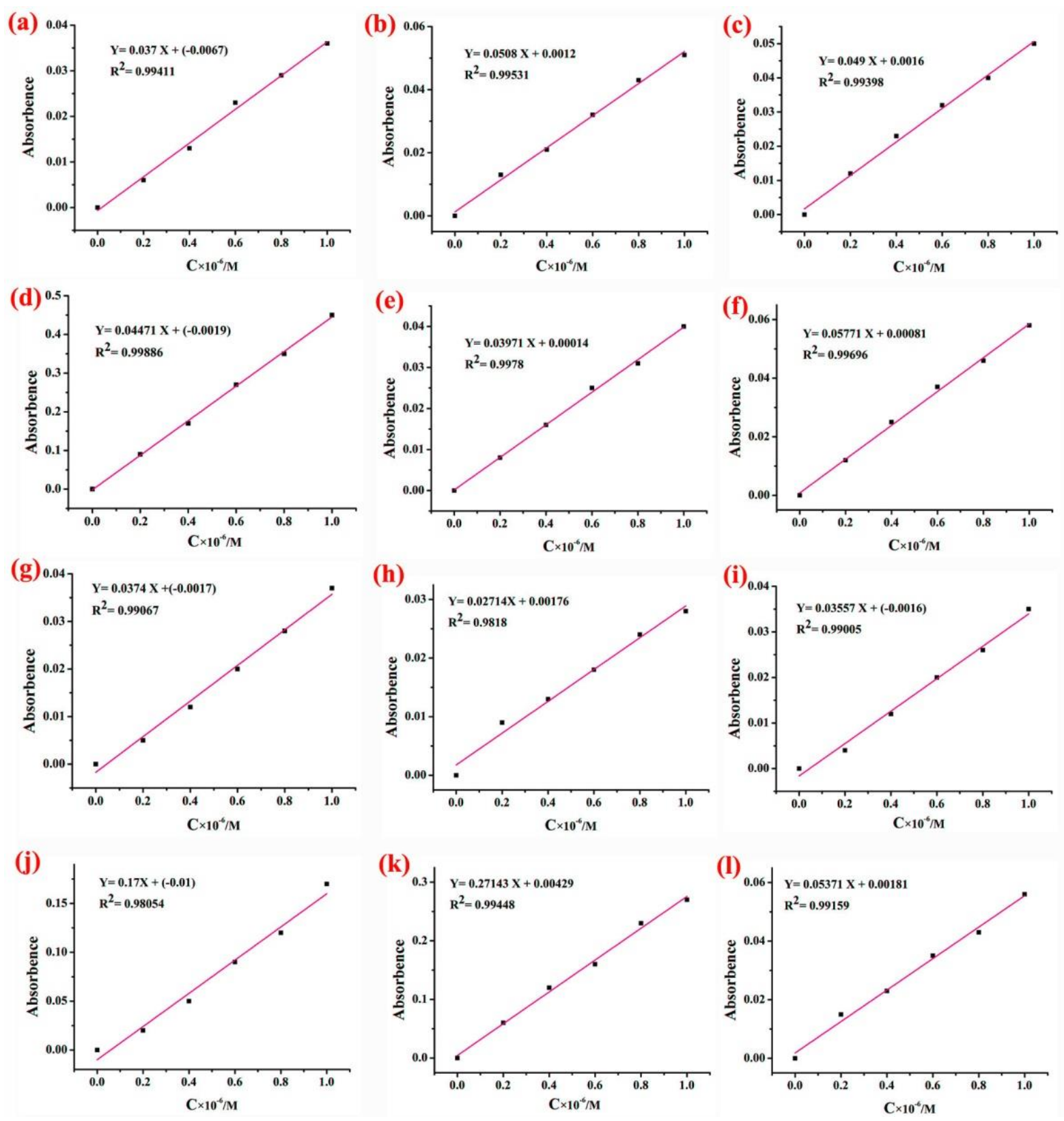

Figure S25. A plot of concentration vs. absorbance intensity is shown. (a) methylene blue; (b) Bismarck brown Y; (c) Giemsa's stain; (d) orangel I; (e) methyl orangel; (f) rhodamine B; (g) Sudan I; (h) Sudan II; (i) picric acid; (j) 1-naphthol; (k) $\mathrm{KMnO}_{4}$; (l) $\mathrm{K}_{2} \mathrm{Cr}_{2} \mathrm{O}_{7}$. 
Table S5. The required contact time to reach equilibrium on the pollutants adsorptions. The amount of the adsorbent used in this study is $0.5 \mathrm{mg} / \mathrm{mL}$.

\begin{tabular}{ccc}
\hline Entry & Pollutants & Equilibrium Time (min) \\
\hline 1 & Methylene Blue & 20 \\
2 & Bismarck Brown Y & 20 \\
3 & Giemsa's Stain & 15 \\
4 & Orangel I & 20 \\
5 & Methyl Orangel & 25 \\
6 & Rhodamine B & 25 \\
7 & Sudan I & 20 \\
8 & Sudan II & 25 \\
9 & Picric Acid & 15 \\
10 & $1-\mathrm{Naphthol}_{1}$ & 20 \\
11 & $\mathrm{KMnO}_{4}$ & 5 \\
12 & $\mathrm{~K}_{2} \mathrm{Cr}_{2} \mathrm{O}_{7}$ & 10 \\
\hline
\end{tabular}


(a)

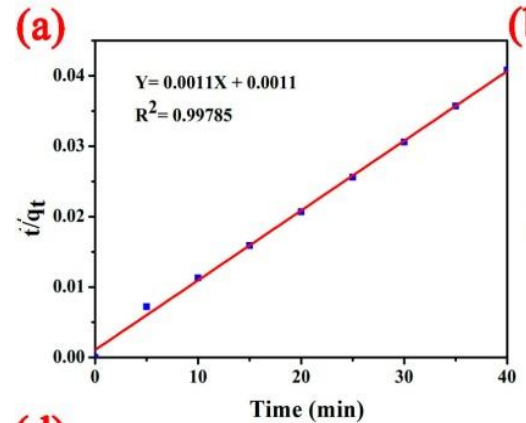

(d)

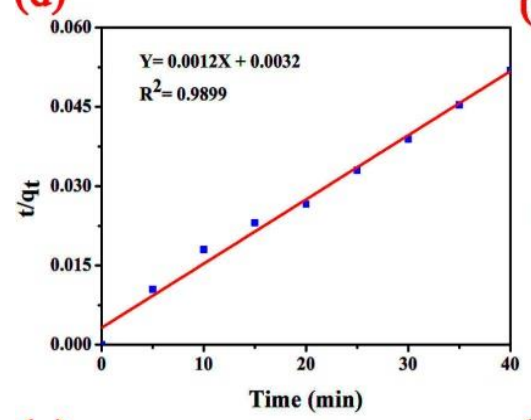

(g)
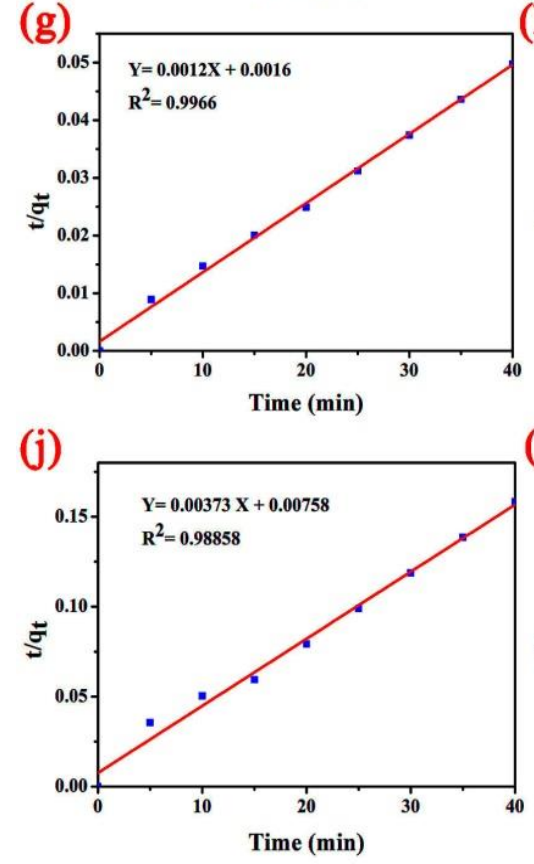

(b)

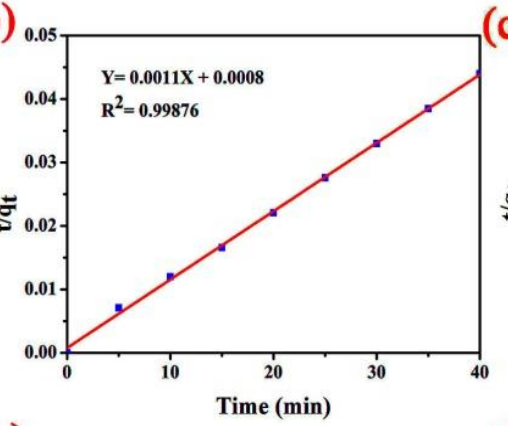

(e)

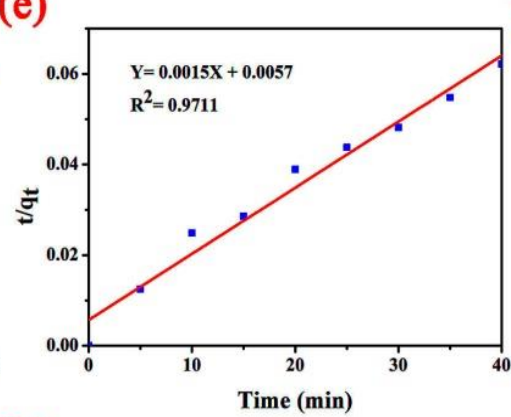

(h)

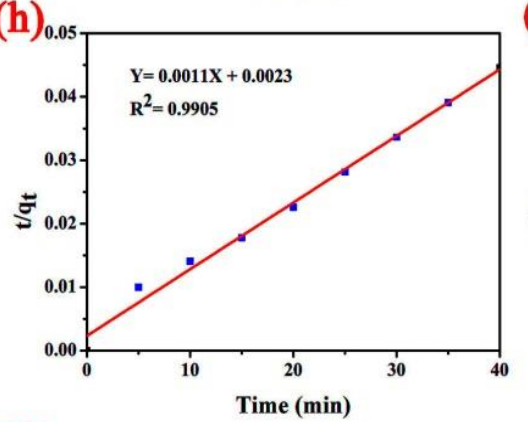

(k)

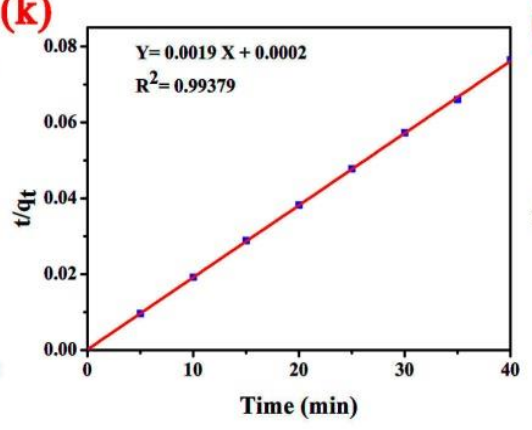

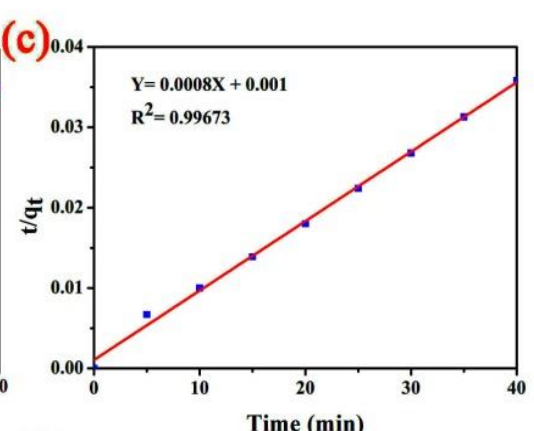

(f)

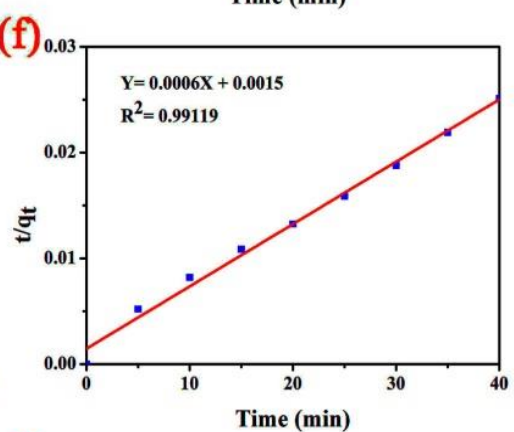

(i)

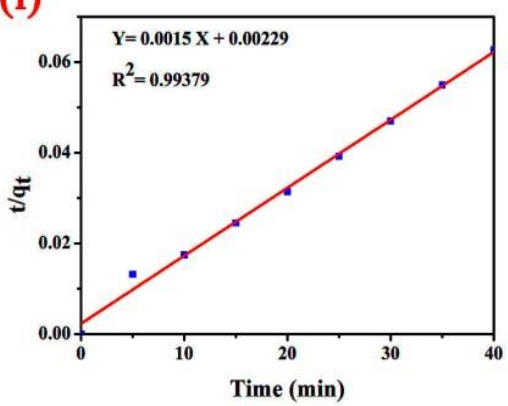

(1)

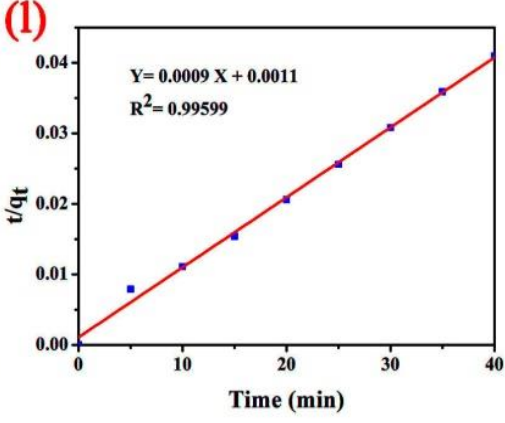

Figure S26. Pseudo-second-order plots for SPN-TDPG: (a) methylene blue; (b) Bismarck brown Y; (c) Giemsa's stain; (d) orangel I; (e) methyl orangel; (f) rhodamine B; (g) Sudan I; (h)Sudan II; (i) picric acid; (j) 1-naphthol; (k) $\mathrm{KMnO}_{4}$; (l) $\mathrm{K}_{2} \mathrm{Cr}_{2} \mathrm{O}_{7}$. Here $t$ (min) is the contact time of each pollutant solution with SPN-TDPG and $q_{\mathrm{t}}(\mathrm{mg} / \mathrm{mg})$ is the amount of each pollutant adsorbed per gram of SPN-TDPG. 
Table S6. Rates of each pollutant uptake by SPN-TDPG.

\begin{tabular}{|c|c|c|c|}
\hline Entry & Pollutants & $k_{\mathrm{obs}} \times 10^{-3}(\mathrm{mg} / \mathrm{mg} \min )$ & $\mathrm{R}^{2}$ \\
\hline 1 & Methylene Blue & 1.10 & 0.99 \\
\hline 2 & Bismarck Brown Y & 1.51 & 0.99 \\
\hline 3 & Giemsa's Stain & 0.64 & 0.99 \\
\hline 4 & Orangel I & 0.45 & 0.99 \\
\hline 5 & Methyl Orangel & 0.39 & 0.97 \\
\hline 6 & Rhodamine B & 0.24 & 0.99 \\
\hline 7 & Sudan I & 0.90 & 0.99 \\
\hline 8 & Sudan II & 0.53 & 0.99 \\
\hline 9 & Picric Acid & 0.98 & 0.99 \\
\hline 10 & 1-Naphthol & 1.83 & 0.99 \\
\hline 11 & $\mathrm{KMnO}_{4}$ & 18.1 & 0.99 \\
\hline 12 & $\mathrm{~K}_{2} \mathrm{Cr}_{2} \mathrm{O}_{7}$ & 0.74 & 0.99 \\
\hline
\end{tabular}



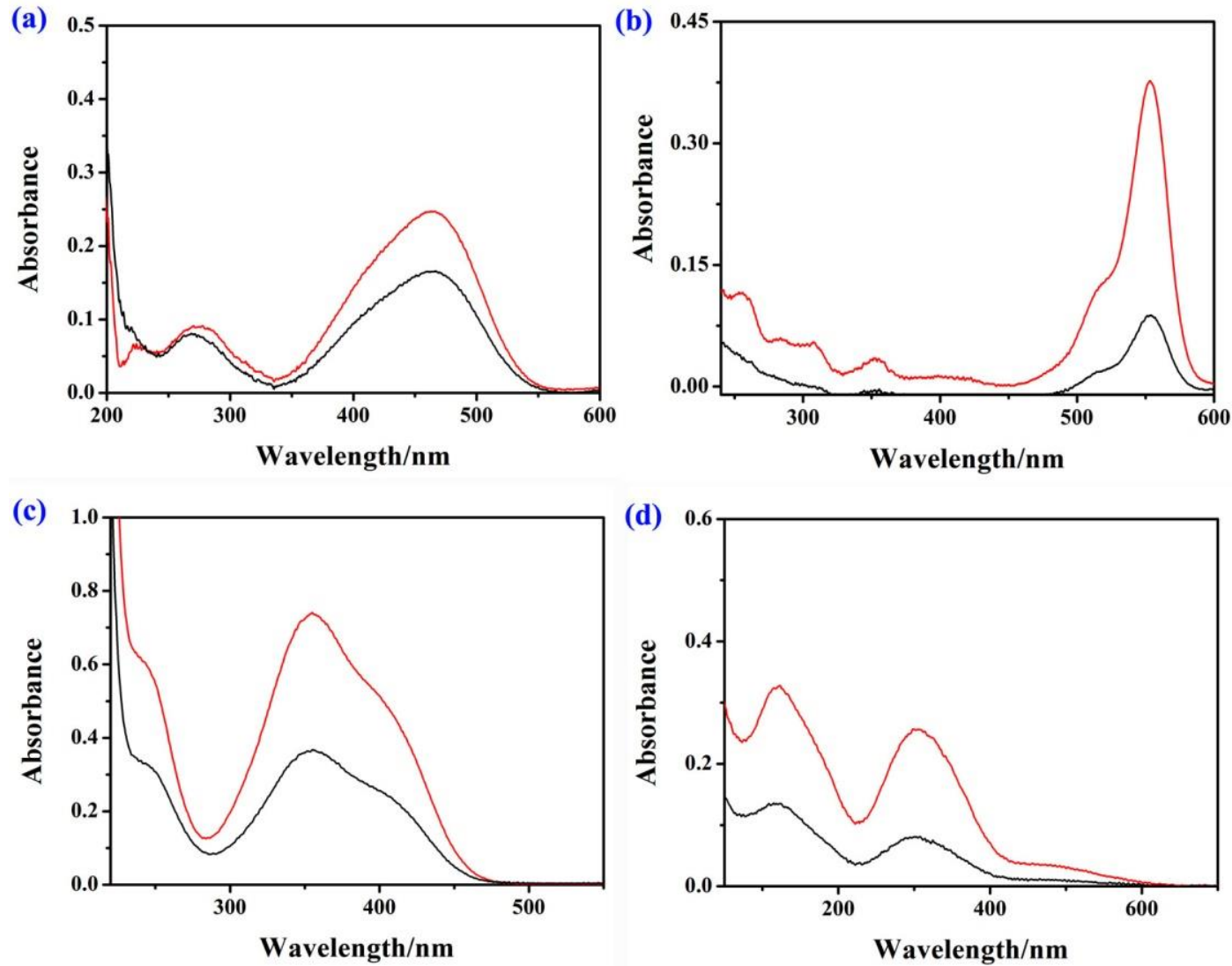

Figure S27. UV-vis spectra recorded before (red line)- after (black line, 40min) of adsorption (a) methyl orange, (b) rhodamine $\mathrm{B}$, (c) picric acid and (d) $\mathrm{K}_{2} \mathrm{Cr}_{2} \mathrm{O}_{7}$ with activated carbon $(0.5 \mathrm{mg} / \mathrm{mL})$.
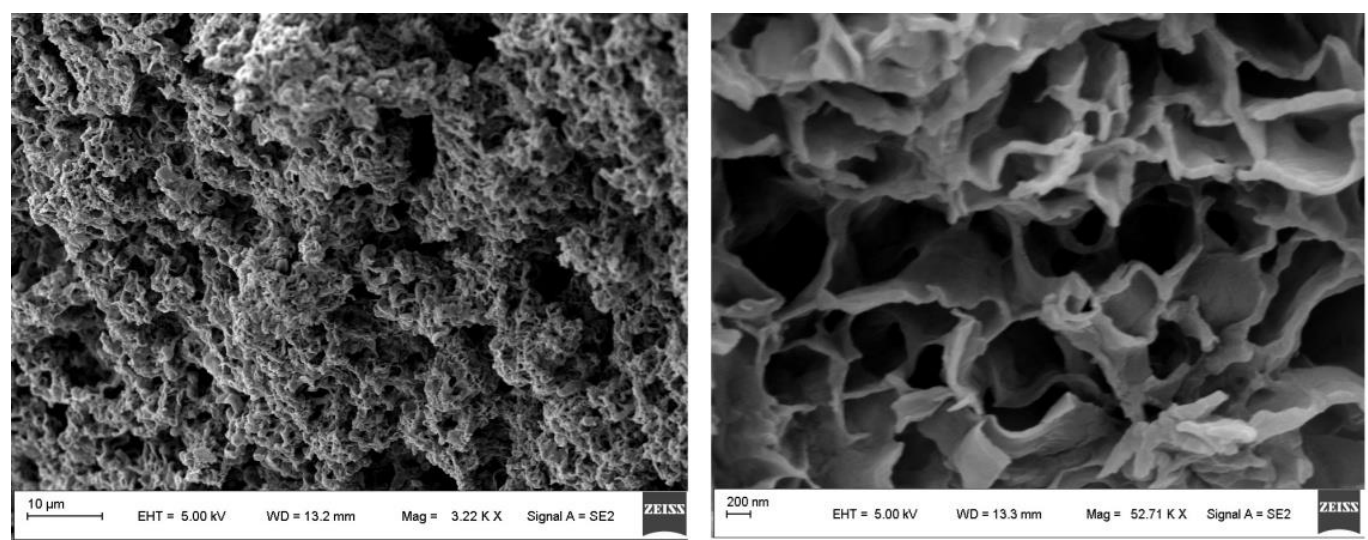

Figure S28. SEM images showing the morphology of regeneration SPN-TDPG. 


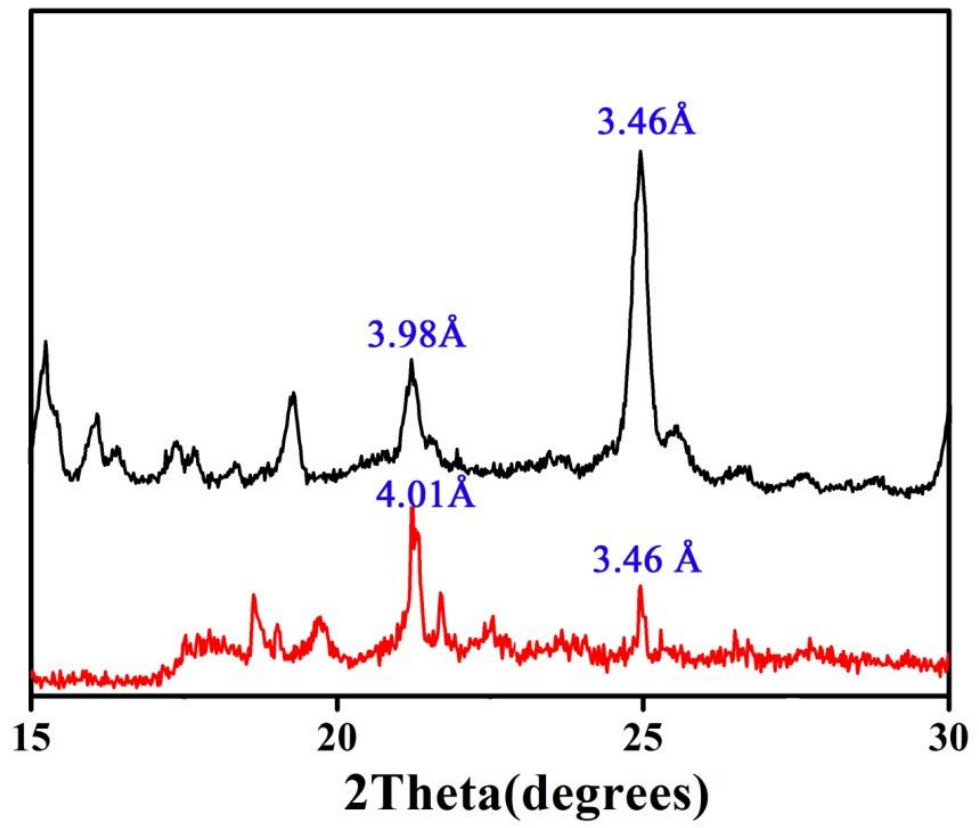

Figure S29. PXRD diagrams of SPN-TDPG and regeneration SPN-TDPG.

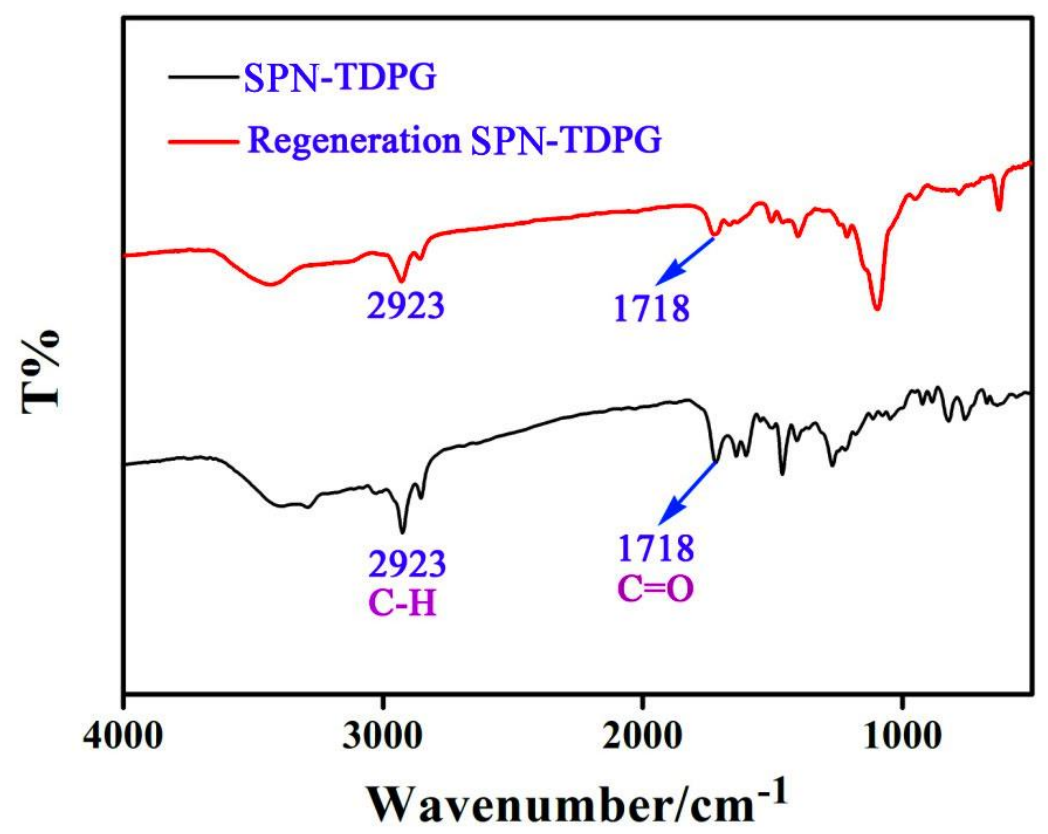

Figure S30. FT-IR spectra of SPN-TDPG and regeneration SPN-TDPG. 


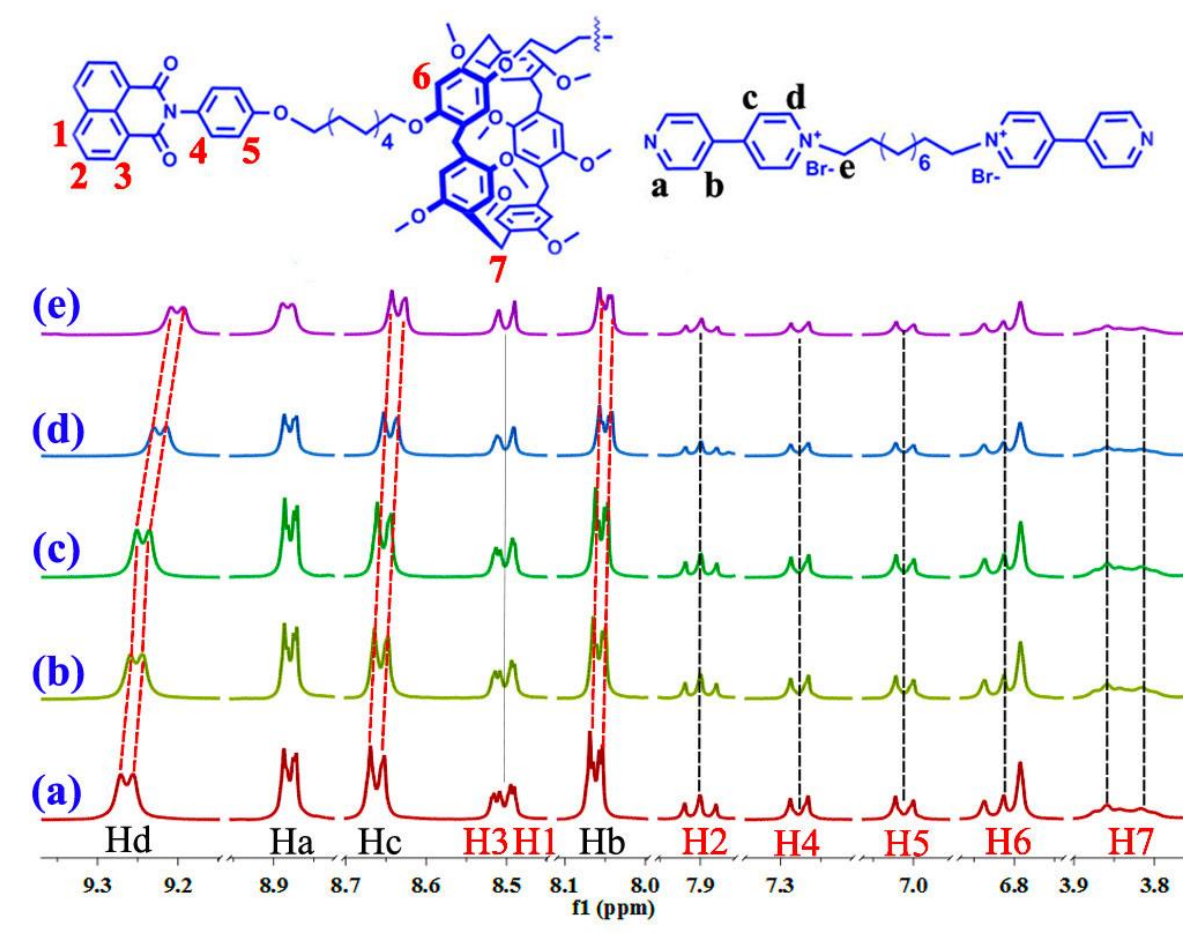

Figure S31. Partial ${ }^{1} \mathrm{H}$ NMR spectra of SPN-TDPG in DMSO- $d_{6}$ with different equivalent $\mathrm{Hg}^{2+}$ (a) 0 equiv.; (b) 0.2 equiv.; (c) 0.5 equiv.; (d) 1.0 equiv.; (e) 1.5 equiv.

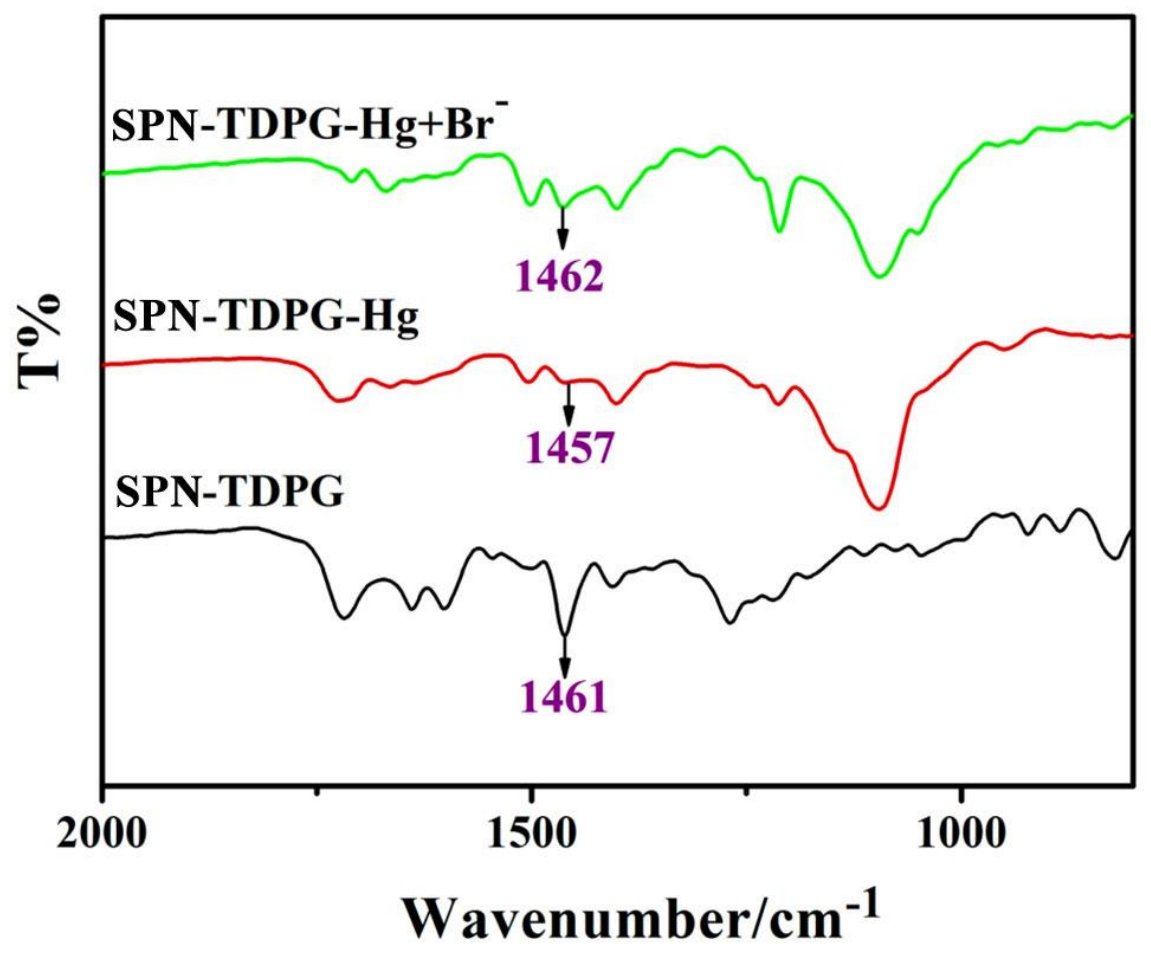

Figure S32. FT-IR spectra of xerogel of SPN-TDPG, SPN-TDPG-Hg and SPN-TDPG-Hg + Br- 

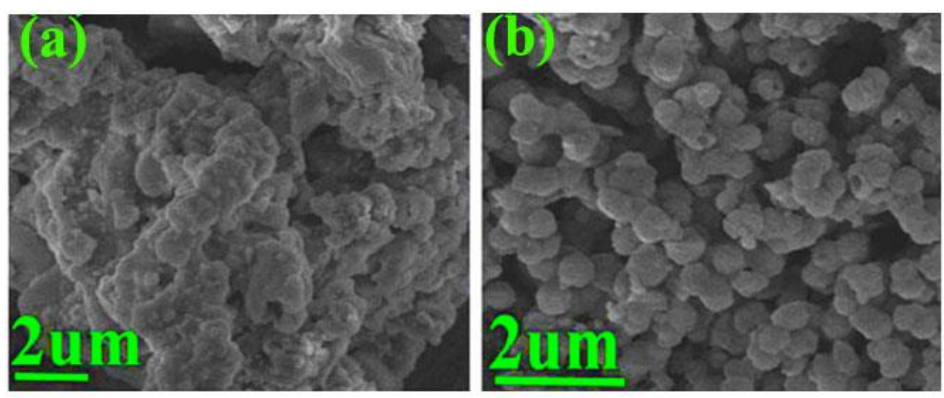

Figure S33. SEM images showing the morphology of (a) SPN-TDPG-Hg; (b) SPN-TDPG-Hg+Br-

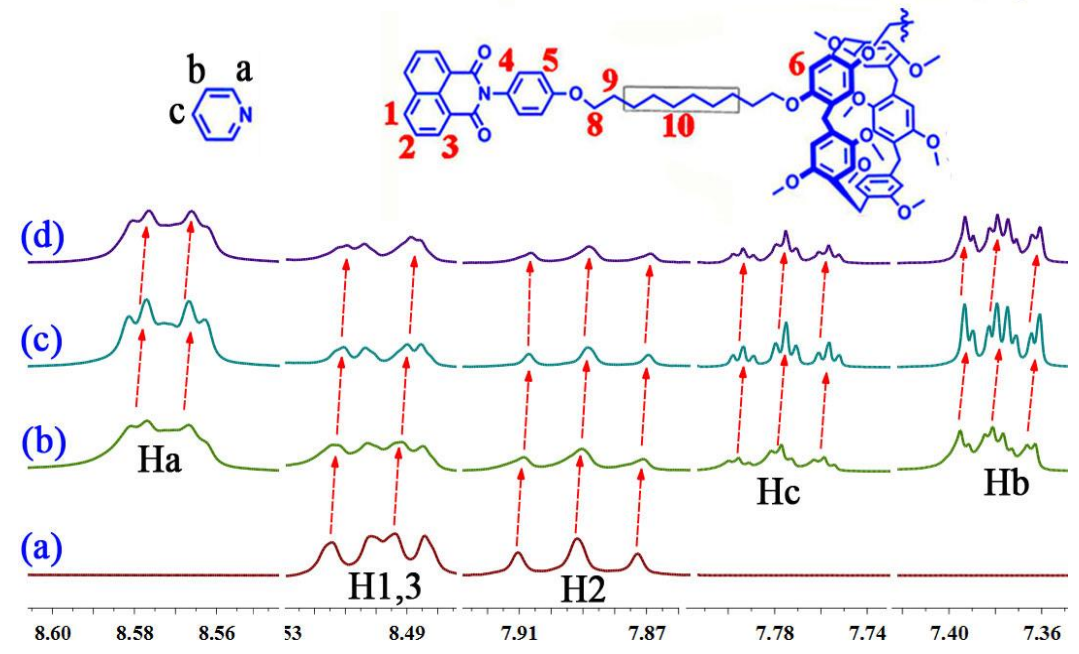

Figure S34. Partial ${ }^{1} \mathrm{H}$ NMR spectra of SPN-TDPG in DMSO- $d_{6}$ with different equivalent pyridine (a) 0 equiv.; (b) 0.2 equiv.; (c) 0.5 equiv.; (d) 1.0 equiv.
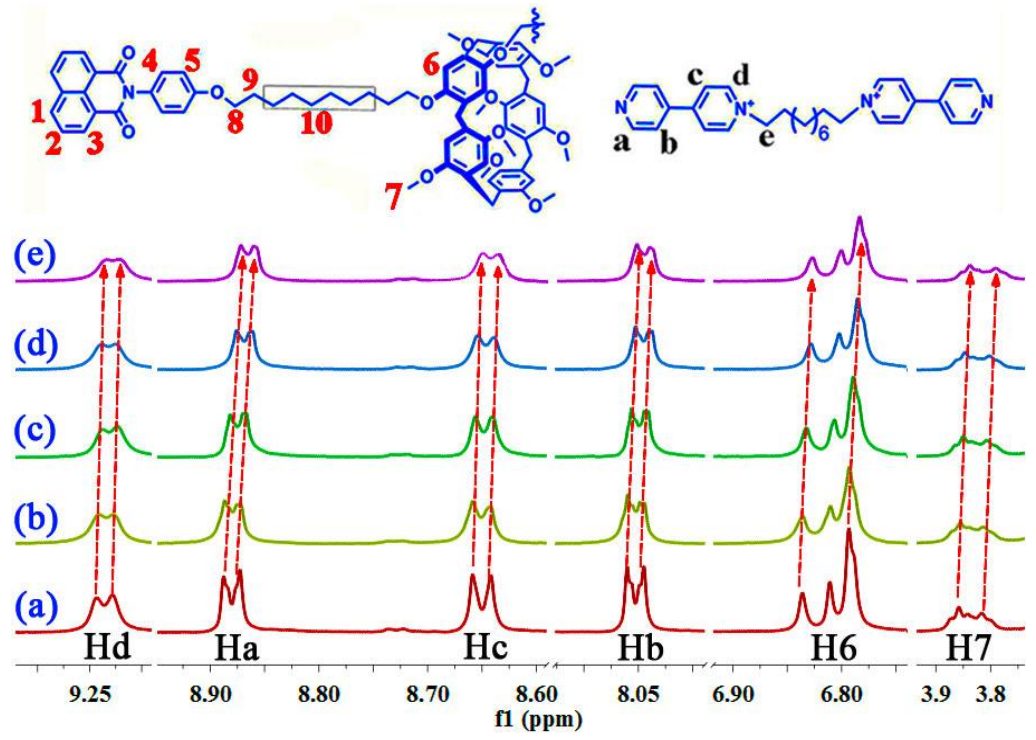

Figure S35. Partial ${ }^{1} \mathrm{H}$ NMR spectra of SPN-TDPG in DMSO- $d_{6}$ with different equivalent $\mathrm{K}_{2} \mathrm{Cr}_{2} \mathrm{O}_{7}$ (a) 0 equiv.; (b) 0.2 equiv.; (c) 0.5 equiv.; (d) 1.0 equiv.; (e) 1.5 equiv. 

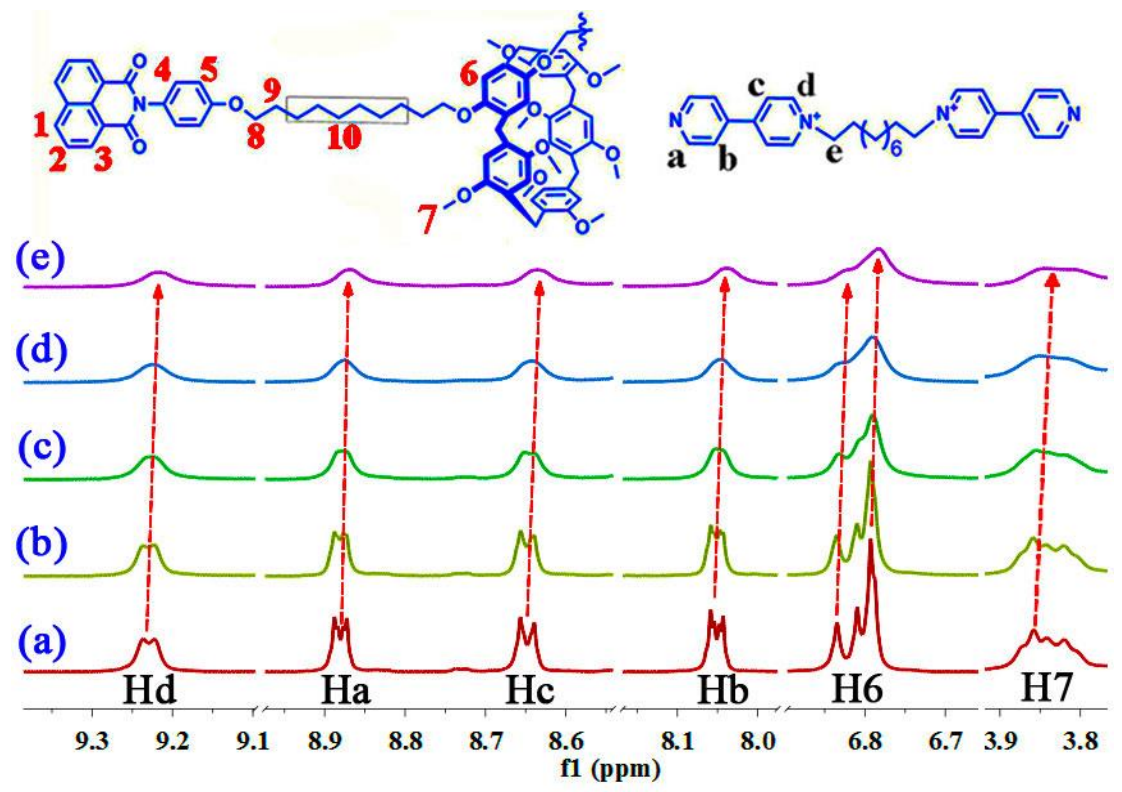

Figure S36. Partial ${ }^{1} \mathrm{H}$ NMR spectra of SPN-TDPG in DMSO- $d_{6}$ with different equivalent $\mathrm{KMnO}_{4}$ (a) 0 equiv.; (b) 0.2 equiv.; (c) 0.5 equiv.; (d) 1.0 equiv.; (e) 1.5 equiv.

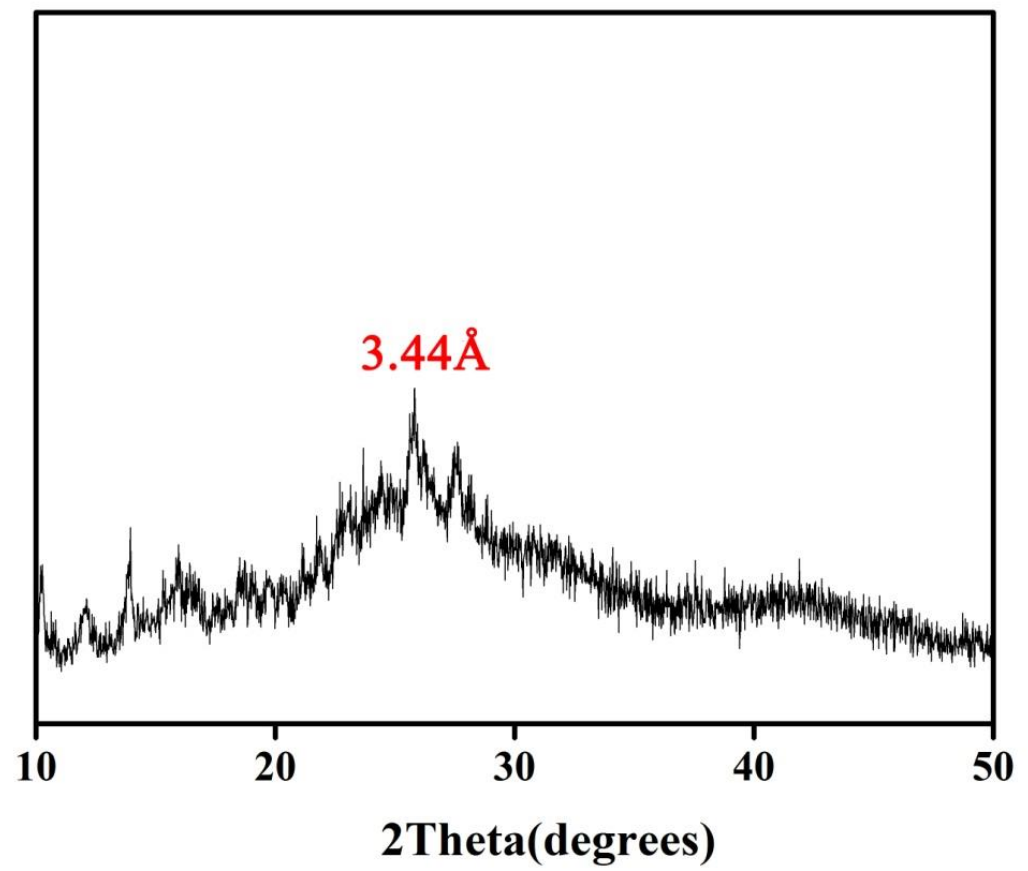

Figure S37. PXRD diagrams of SPN-TDPG adsorb rhodamine B. 


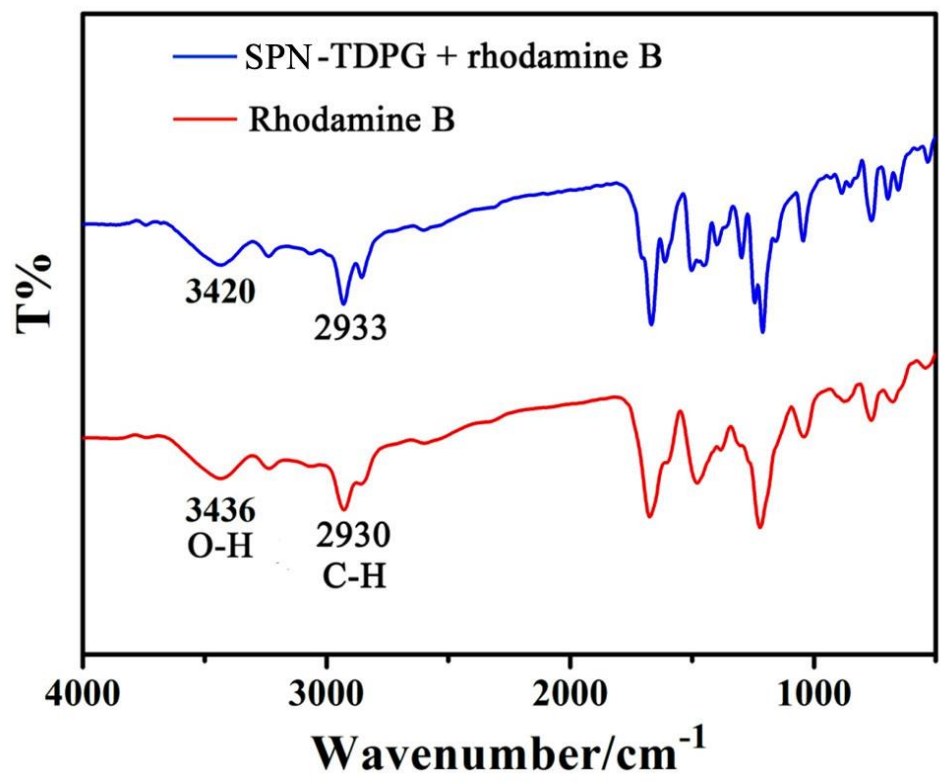

Figure S38. FT-IR spectra of SPN-TDPG adsorb rhodamine B.
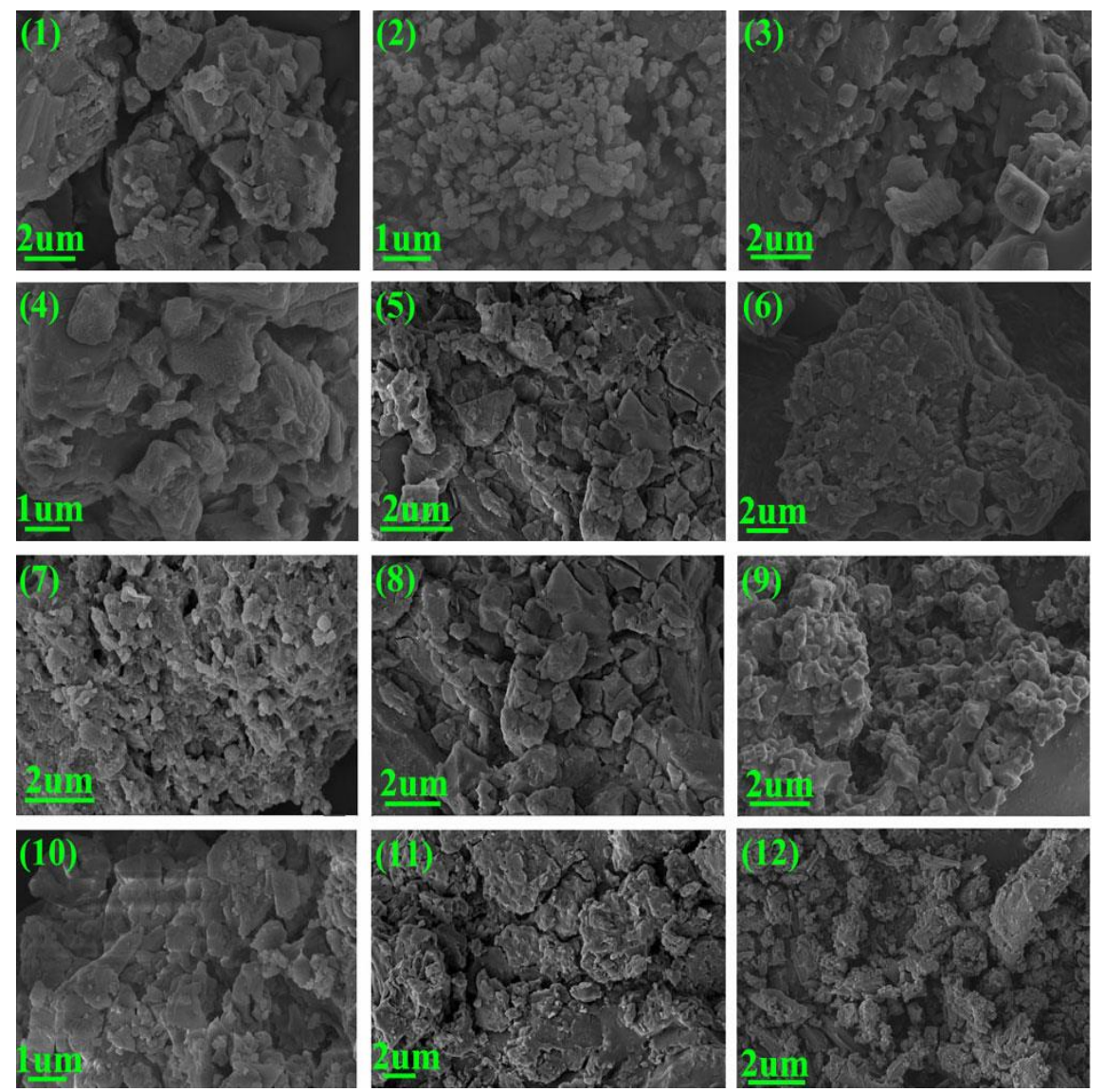

Figure S39. Representative SEM images showing the morphology of SPN-TDPG adsorbed (1) methylene blue; (2) bismarck brown Y; (3) giemsa's stain; (4) orangel I; (5) methyl orangel; (6)rhodamine B; (7) sudan I; (8) sudan II; (9) picric acid; (10) 1-naphthol; (11) $\mathrm{KMnO}_{4}$; (12) $\mathrm{K}_{2} \mathrm{Cr}_{2} \mathrm{O}_{7}$. 


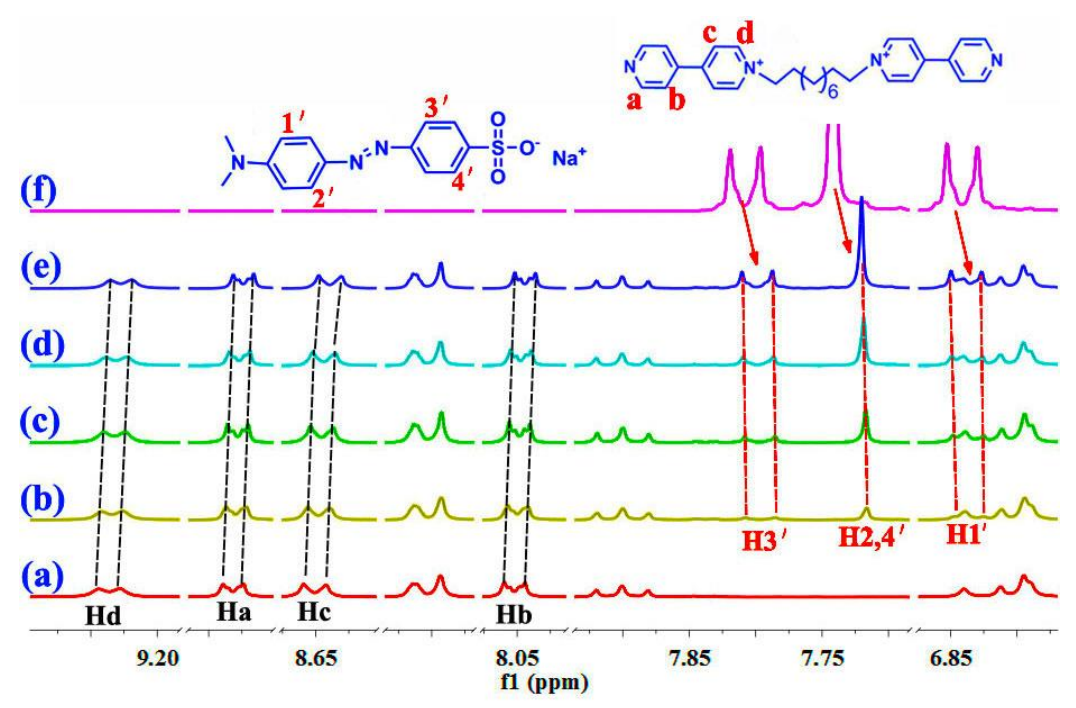

Figure S40. Partial ${ }^{1} \mathrm{H}$ NMR titration spectra $(600 \mathrm{MHz}, 298 \mathrm{~K})$ of $3.0 \mathrm{mM}$ SPN-TDPG with various equivalents of methyl orangel in DMSO- $d_{6}$ solution. (a) SPN-TDPG; (b) 0.5 equiv.; (c) 1.0 equiv.; (d) 2.0 equiv.; (e) 3.0 equiv.; (f) methyl orangel.

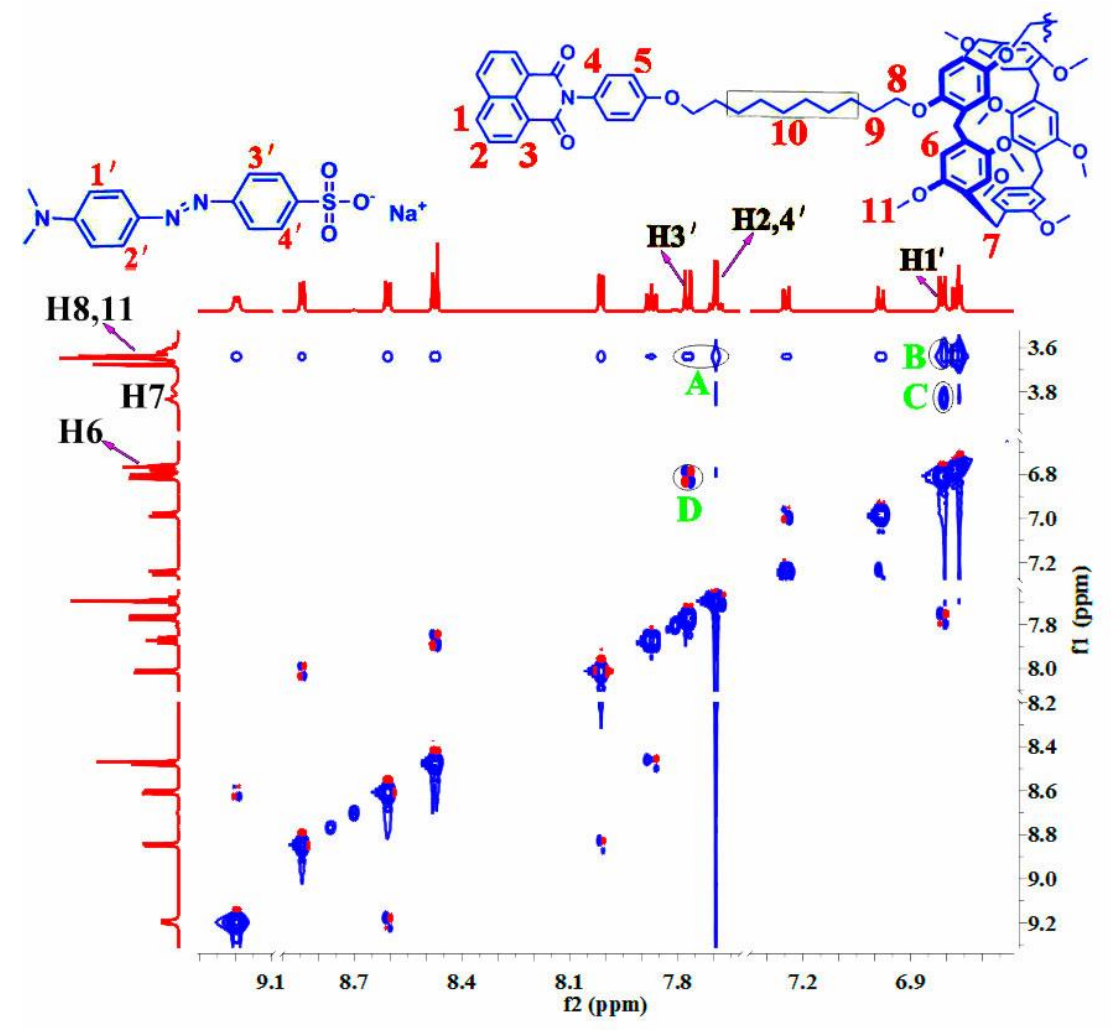

Figure S41. Partial 2D NOESY NMR spectrum of 3.0 mM SPN-TDPG and methyl orangel in DMSO- $d_{6}$ solution $(600 \mathrm{MHz}, 298 \mathrm{~K})$. 


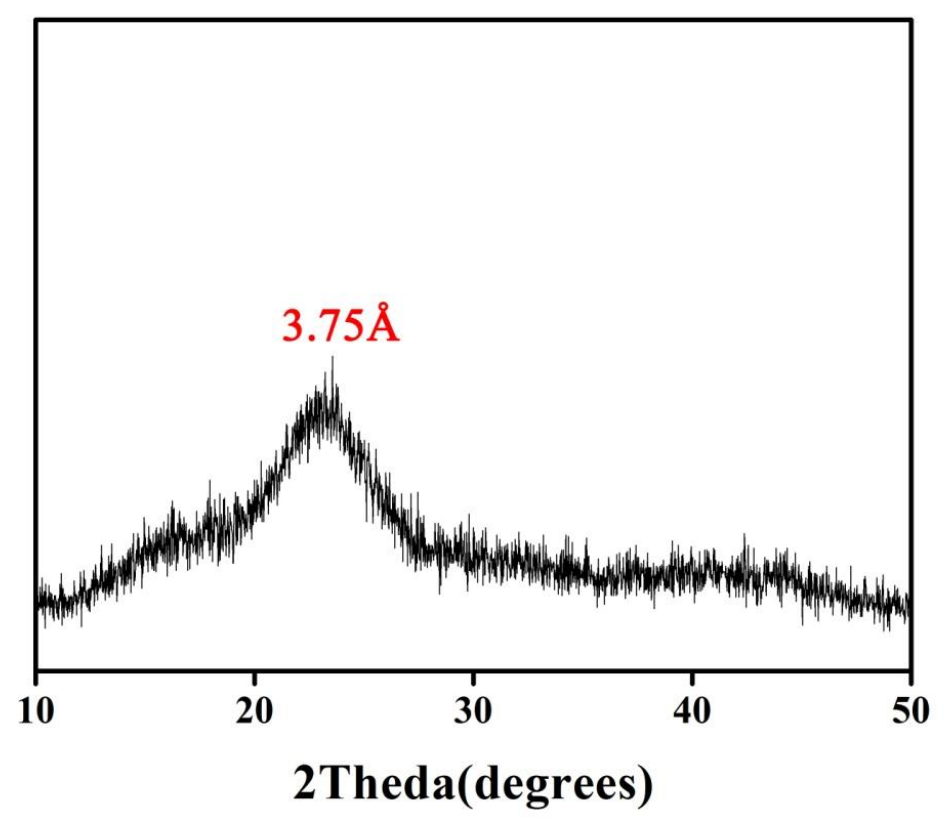

Figure S42. PXRD diagrams of SPN-TDPG adsorb methyl orange.

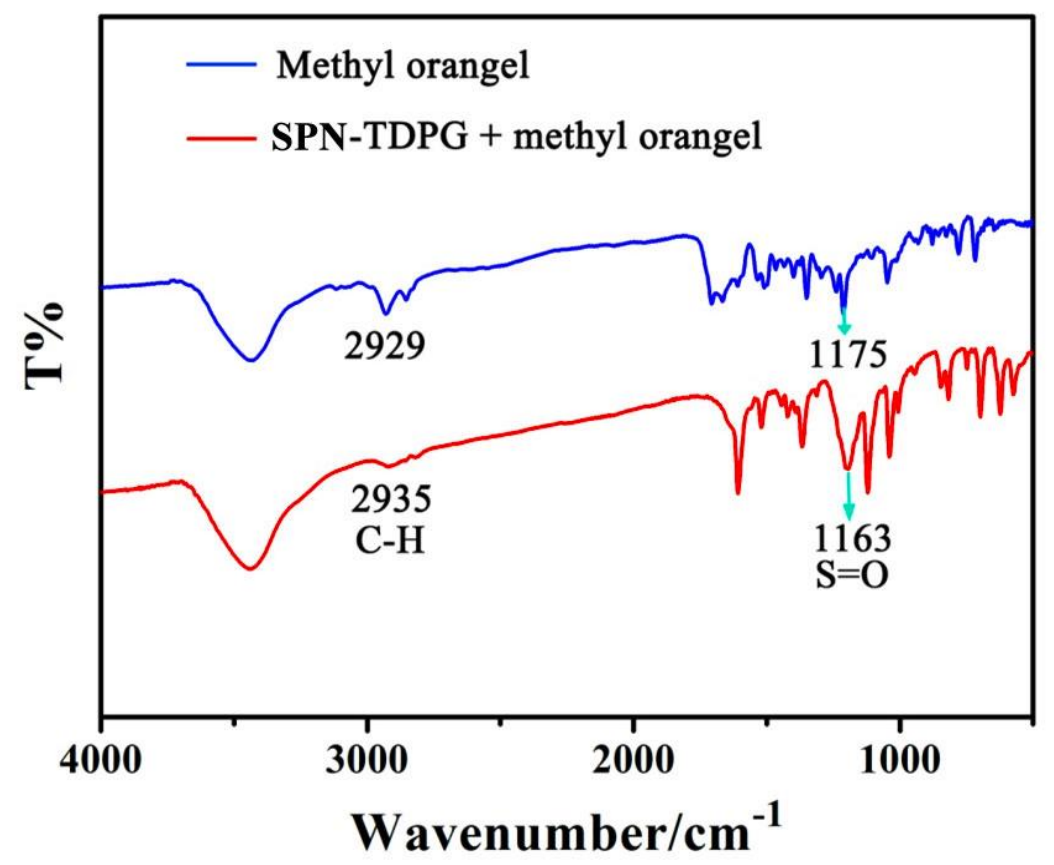

Figure S43. FT-IR spectra of SPN-TDPG adsorb methyl orange. 


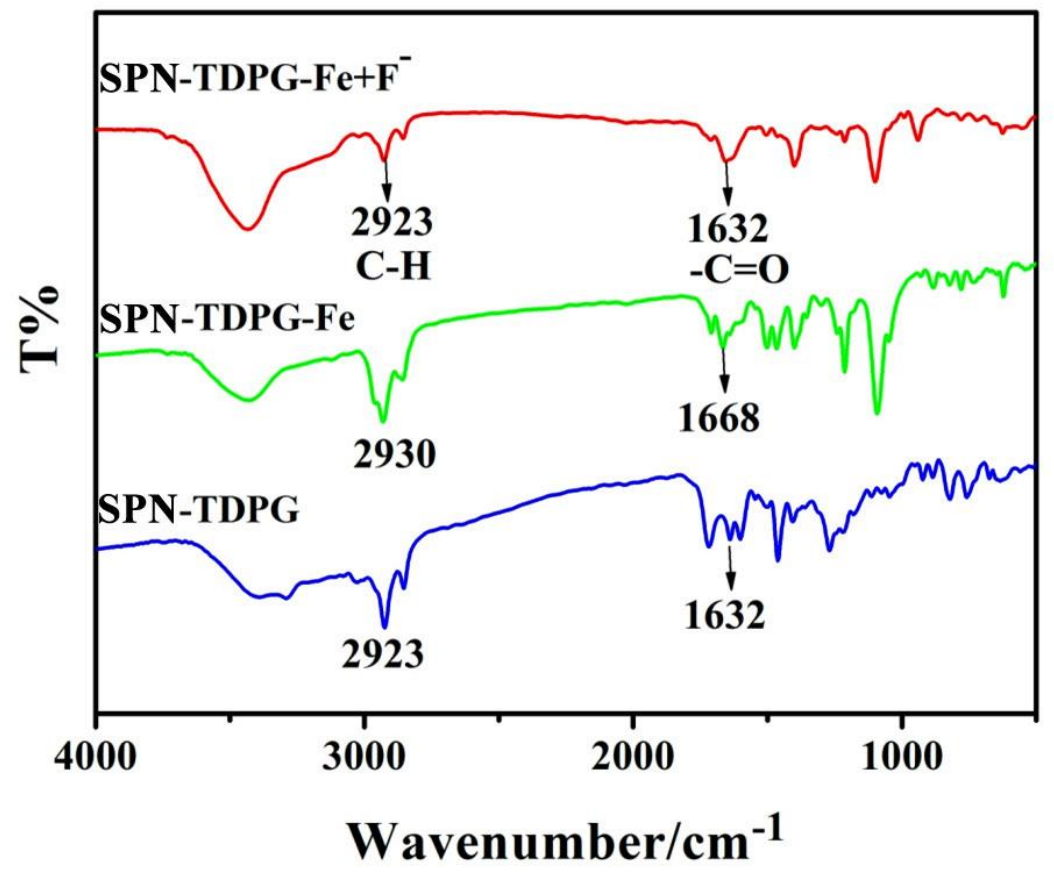

Figure S44. FT-IR spectra of xerogel SPN-TDPG, SPN-TDPG-Fe and SPN-TDPG-Fe + F $^{-}$
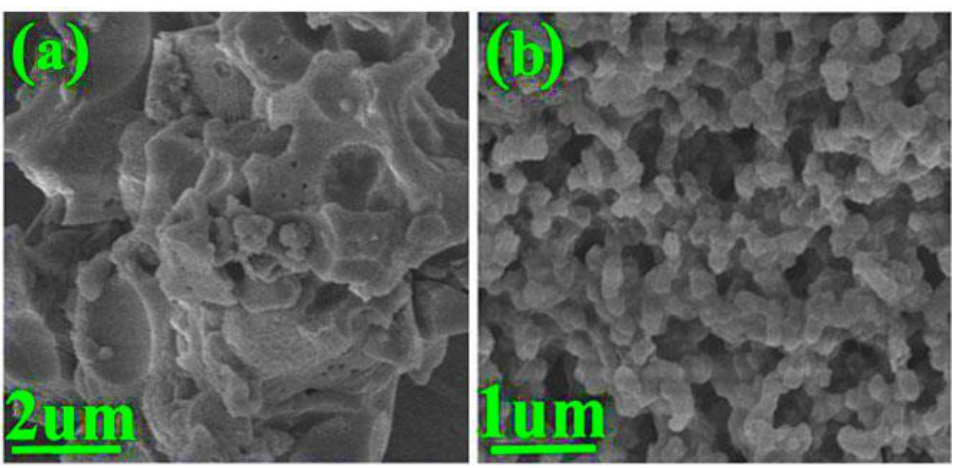

Figure S45. Representative SEM images showing the morphology of (a) SPN-TDPG-Fe; (b) SPN-TDPG-Hg; (c) SPN-TDPG-Fe+F-; (d) SPN-TDPG-Hg+Br- 